\title{
Considerations for the use of Cre recombinase for conditional gene deletion in the mouse lens
}

Phuong T. Lam', Stephanie L. Padula', Thanh V. Hoang ${ }^{1,8}$, Justin E. Poth', Lin Liu', Chun Liang ${ }^{1}$, Adam S. LeFever², Lindsay M. Wallace ${ }^{3}$, Ruth Ashery-Padan ${ }^{4}$, Penny K. Riggs ${ }^{5}$, Jordan E. Shields ${ }^{5,9}$, Ohad Shaham ${ }^{4}$, Sheldon Rowan ${ }^{6}$, Nadean L. Brown ${ }^{7}$, Tom Glaser ${ }^{7}$ and Michael L. Robinson ${ }^{1 *}$ (D)

\begin{abstract}
Background: Despite a number of different transgenes that can mediate DNA deletion in the developing lens, each has unique features that can make a given transgenic line more or less appropriate for particular studies. The purpose of this work encompasses both a review of transgenes that lead to the expression of Cre recombinase in the lens and a comparative analysis of currently available transgenic lines with a particular emphasis on the Le-Cre and P0-3.9GFPCre lines that can mediate DNA deletion in the lens placode. Although both of these transgenes are driven by elements of the Pax6 P0 promoter, the Le-Cre transgene consistently leads to ocular abnormalities in homozygous state and can lead to ocular defects on some genetic backgrounds when hemizygous.

Result: Although both P0-3.9GFPCre and Le-Cre hemizygous transgenic mice undergo normal eye development on an FVB/N genetic background, Le-Cre homozygotes uniquely exhibit microphthalmia. Examination of the expression patterns of these two transgenes revealed similar expression in the developing eye and pancreas. However, lineage tracing revealed widespread non-ocular CRE reporter gene expression in the P0-3.9GFPCre transgenic mice that results from stochastic CRE expression in the P0-3.9GFPCre embryos prior to lens placode formation. Postnatal hemizygous Le-Cre transgenic lenses express higher levels of CRE transcript and protein than the hemizygous lenses of P0-3.9GFPCre mice. Transcriptome analysis revealed that Le-Cre hemizygous lenses deregulated the expression of 15 murine genes, several of which are associated with apoptosis. In contrast, P0-3.9GFPCre hemizygous lenses only deregulated two murine genes. No known PAX6-responsive genes or genes directly associated with lens differentiation were deregulated in the hemizygous Le-Cre lenses.

Conclusions: Although P0-3.9GFPCre transgenic mice appear free from ocular abnormalities, extensive non-ocular CRE expression represents a potential problem for conditional gene deletion studies using this transgene. The higher level of CRE expression in Le-Cre lenses versus P0-3.9GFPCre lenses may explain abnormal lens development in homozygous Le-Cre mice. Given the lack of deregulation of PAX6-responsive transcripts, we suggest that abnormal eye development in Le-Cre transgenic mice stems from CRE toxicity. Our studies reinforce the requirement for appropriate CRE-only expressing controls when using CRE as a driver of conditional gene targeting strategies.
\end{abstract}

Keywords: Cre recombinase, Lens development, Transgenic mice

\footnotetext{
* Correspondence: robinsm5@miamioh.edu

'Department of Biology, Miami University, Oxford, OH 45056, USA

Full list of author information is available at the end of the article
}

C The Author(s). 2019 Open Access This article is distributed under the terms of the Creative Commons Attribution 4.0 International License (http://creativecommons.org/licenses/by/4.0/), which permits unrestricted use, distribution, and reproduction in any medium, provided you give appropriate credit to the original author(s) and the source, provide a link to the Creative Commons license, and indicate if changes were made. The Creative Commons Public Domain Dedication waiver (http://creativecommons.org/publicdomain/zero/1.0/) applies to the data made available in this article, unless otherwise stated. 


\section{Background}

Few breakthroughs have transformed the field of genetic engineering more than the discovery and exploitation of site-specific DNA recombinases. While gene mutations provide essential insight into normal gene function, early embryonic lethality often limits the information provided by a constitutive deletion (knockout) of essential, multifunctional genes. Solutions for this limitation came from the development of microorganism-derived, site-specific DNA recombinases. These recombinases include Cre (derived from P1 bacteriophage [1]), Flp (derived from S. cerevisiae [2]), and Dre (derived from D6 bacteriophage [3]). Cre, Flp, and Dre utilize 34 bp loxP, $34 \mathrm{bp}$ Frt, or $32 \mathrm{bp}$ rox recombination recognition sequences, respectively [4]. Each enzyme catalyzes recombination between two copies of their specific recognition sequence resulting in integration, deletion, translocation, or inversion of DNA, depending on the location and orientation of the recognition sequences [5]. Among these, Cre recombinase (CRE) remains the most widely used for mammalian genetic engineering. In fact, the Mouse Genome Informatics database (http://www.informatics.jax.org/) contains more than 2500 CRE transgenes and is annotated with information about expression pattern, current availability, and relevant publications.

Geneticists first demonstrated the ability of CRE to mediate DNA recombination in a living mammal using the lens as an experimental platform. In this pioneering experiment, CRE recombination activated the expression of the SV40 large tumor antigen (TAg), exclusively in the developing lenses of transgenic mice [6]. Specifically, the mouse $\alpha \mathrm{A}$-crystallin promoter drove transgenic CRE expression in the lens to catalyze the deletion of a loxP-flanked (floxed) transcriptional termination sequence that blocked TAg expression from a separate transgene. The resultant bi-transgenic mice carrying both the CRE transgene ( $m \alpha A$-Cre) and the TAg-bearing transgene uniformly developed lens tumors. Although mice never spontaneously develop lens tumors, the potency of the SV40 TAg for tumor formation meant that only a few lens cells in the bi-transgenic mice would have to undergo CRE-mediated recombination for tumor formation to occur. However, subsequent experiments demonstrated that CRE catalyzed DNA recombination in mice with very high efficiency, spurring the creation of hundreds of different transgenic mouse lines with inducible and/or tissue-specific CRE expression [7]. Insertion of loxP sites within introns usually has little or no effect on host gene expression. Hence, CRE revolutionized functional genomics by limiting the pattern and onset of gene deletion.

Although $m \alpha A$-Cre mice no longer exist, other CRE transgenes continue to facilitate studies of gene function in the developing lens (Fig. 1). MLR39 and MLR10 transgenes, like $m \alpha A-C r e$, utilize the mouse $\alpha \mathrm{A}$-crystallin promoter to express CRE in developing lens fiber cells. In MLR10, an engineered insertion of a Pax6 consensus-binding site within the transgenic $\alpha \mathrm{A}$-crystallin promoter drives transgene expression in the lens epithelium as well [8]. Several transgenes including Le-Cre [9], Pax6(Lens)-Cre [10], LR-Cre [11], and P0-3.9GFPCre [12], utilized different mouse Pax6 P0 promoter/ectodermal enhancer sequences to drive CRE expression in the lens. Although designed to express CRE in neuronal and glial progenitor cells, the Nes-Cre transgenic mice made with the rat Nestin promoter/enhancer [13] is also active in the lens [14-16]. Of these transgenic mice, the most commonly used are (in order of use frequency to date) $\mathrm{Le}$-Cre (62 publications), MLR10 (28 publications), MLR39, (7 publications), Nes-Cre (3 publications), P0-3.9GFPCre (4 publications), and $\mathrm{LR}$-Cre (3 publications). Like the $m \alpha A$-Cre transgenics, the Pax6(Lens)-Cre mice [10] no longer exist. Each of these transgenes resulted from non-targeted DNA integrations into the genome following zygote microinjection.

The CRE tissue expression pattern represents the most important consideration to decide which of the available CRE transgenic lines will best suit any given project. However, the chromosomal location into which microinjected DNA constructs insert often affects transgene expression. These position effects frequently lead to unintended expression patterns or mosaic transgene expression [17-19]. Also, multiple tandem transgene copies, present in most transgenic lines produced by microinjection, may undergo epigenetic transcriptional silencing over time [20]. Despite these complications, each of the available CRE transgenic lines have distinct features that may provide unique advantages for some experimental purposes. Until now, no comparative analysis of CRE lines existed for lens gene deletion despite the usefulness of this information for future experimental designs.

CRE transgenes driven by P0 promoter/ectodermal enhancer of the mouse Pax6 gene can mediate floxed gene deletion in the head surface ectoderm, which includes the lens placode, at embryonic day 9.0 (E9.0). In addition to catalyzing widespread deletion in the lens, these transgenes also result in floxed DNA deletion in precursors of the corneal epithelium, eyelid epithelium, conjunctiva, and surface ectoderm-derived ocular glands. The transgenic constructs used to produce the Le-Cre and P0-3.9GFPCre mice contain a large DNA fragment upstream of the murine Pax6 P0 promoter, including the ectodermal enhancer as well as proximal and distal enhancers active in the endocrine pancreas [21-24]. As a result, both $\mathrm{Le}$-Cre and PO-3.9GFPCre transgenic lines 


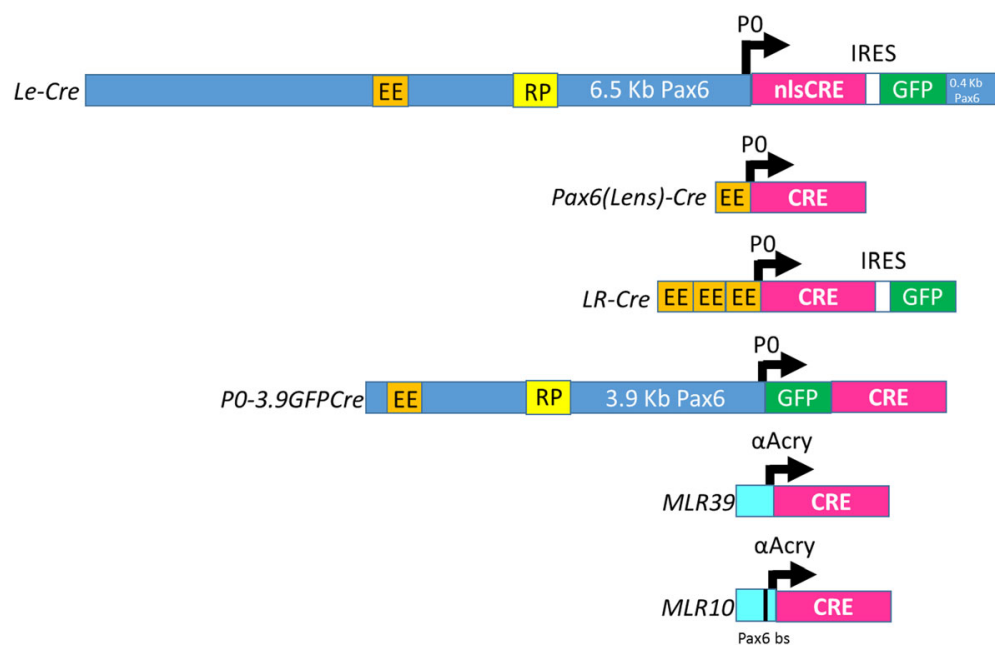

Fig. 1 DNA constructs used to make Cre-expressing transgenic mouse lines. Black arrows represent the transcription start sites for the mouse Pax6 P0 promoter (blue in the Le-Cre and P0-3.9GFPCre constructs) or the mouse aA-crystallin promoter (light blue in the MLR39 and MLR10 constructs). The pink and green boxes represent CRE and GFP coding sequences, respectively. The thin black line within the aA-crystallin promoter in the MLR10 construct represents the engineered Pax6 binding site. The orange EE and yellow RP boxes represent the Pax6 ectodermal enhancer element and the retina/pancreas enhancer elements, respectively. The IRES (white box in the Le-Cre construct) stands for internal ribosome entry site, and nlsCre stands for Cre recombinase with an added nuclear localization sequence. There is approximately 400 bp of mouse Pax6 sequence from the first intron included at the $3^{\prime}$ end of the Le-Cre transgenic construct, following the GFP coding sequence

exhibit CRE expression in pancreatic precursors by E8.5, even earlier than in the presumptive lens ectoderm. Unlike the Le-Cre mice, the P0-3.9GFPCre mice expressed CRE in the apical ectodermal ridge in the limb buds and in the stomach mesenchyme [25]. The transgenic construct used to create the Pax6(Lens)-Cre mice contained only the 340 bp ectodermal enhancer and minimal Pax6 P0 promoter, explaining the lack of pancreatic CRE expression in this mouse line [10]. Also, while transgene expression in the Le-Cre and P0-3.9GFPCre lines include both the lens placode and a swath of the head surface ectoderm extending to the olfactory epithelium, the Pax6(Lens)-Cre mice exhibited a more restricted, lens placode-proximal, expression pattern. Like the Pax6(Lens)-Cre transgene construct, the construct used to create the LR-Cre mice lacked the pancreatic Pax6 enhancers, but this construct contained three tandem copies of the ectodermal enhancer cloned upstream of the Pax6 P0 promoter. Transgene expression in the $L R$-Cre mice occurred in both the surface ectoderm encompassing the lens placode and in the optic vesicle at E9.5 [11]. Therefore, in contrast to the other CRE transgenes driven by the Pax6 P0 promoter, the LR-Cre transgene catalyzes floxed DNA deletion in both the ocular surface ectoderm and in the presumptive neural retina.

Utilizing the $366 \mathrm{bp}$ murine $\alpha \mathrm{A}$-crystallin promoter to drive CRE expression to the developing lens, MLR10 and MLR39 transgenes act later in development, and more lens-specifically, than those driven by the Pax6 P0 promoter. Unlike the endogenous mouse $\alpha \mathrm{A}$-crystallin promoter, the $366 \mathrm{bp}$ murine $\alpha \mathrm{A}$-crystallin promoter fragment lacks several lens-specific enhancer elements that support expression in the lens epithelium [26]. As a result, transgenes driven by this promoter fragment usually initiate expression around E12.5 and typically exclude the prenatal lens epithelium. The transgenic construct used to create the MLR10 mice included a 20 bp consensus PAX6 binding site [27] embedded in the $366 \mathrm{bp}$ mouse $\alpha \mathrm{A}$-crystallin promoter. CRE expression in MLR10 mice initiates in the lens vesicle at E10.5 and mediates floxed DNA deletion in both the lens fiber cells and lens epithelium [8]. In addition, MLR10 transgene expression in the eye remains lens-specific. In contrast, the MLR39 transgene construct, consisting only of the 366 bp murine $\alpha A$-crystallin promoter fragment, leads to the initiation of CRE expression in lens fiber cells at E12.5 without expression in the developing lens epithelium [8]. However, co-injection of the $\alpha A$-crystallin/CRE construct with a mouse tyrosinase minigene produced light coat pigmentation in albino MLR39 transgenic mice. Co-integration of the CRE transgene with the tyrosinase minigene, which normally leads to tyrosinase expression in melanocytes and retinal pigmented epithelium (RPE), provides an explanation of why this transgenic line initiates mosaic CRE expression in the RPE at E11.5.

A number of other CRE transgenes effectively delete floxed DNA in the developing lens, but these often exhibit a widespread deletion in other tissues. The Nes-Cre 
transgenic mice, for example, exhibit floxed gene deletion throughout the nervous system as well as in the lens epithelial cells and fiber cells $[13,14]$. The $A p 2 \alpha-I R-$ ESCre transgenic line catalyzes floxed DNA deletion in the presumptive lens ectoderm even earlier than those transgenic lines driven by the Pax6 P0 promoter, but CRE expression in these mice includes large portions of head and trunk surface ectoderm and neural crest cells [28]. Also, the Ap2 $\alpha$-IRESCre mice resulted from targeted insertion of CRE into the endogenous Tcfap $2 \alpha$ gene in embryonic stem cells rather than from zygote microinjection. While the Nes-Cre and Ap2 $\alpha$-IRESCre mice remain useful for lens gene deletion in particular contexts, the widespread, non-ocular expression exhibited by these transgenes limits their utility. For this reason, lens biologists more frequently use the more limited expression pattern of the Le-Cre and MLR10 transgenic strains for gene deletion within the lens. Table 1 summarizes the published information currently available concerning the CRE transgenic lines with lens activity.

Despite its widespread use, the Le-Cre transgene sometimes disrupts lens development independent of any floxed DNA deletion. The first report of cataracts and microphthalmia associated with homozygous $\mathrm{Le}$-Cre transgenic mice appeared more than a decade ago [29]. More recently, investigators have documented lens and cornea abnormalities in Le-Cre hemizygous mice, the severity of which varied on different genetic backgrounds $[30,31]$. These observations demonstrate the necessity of including hemizygous $\mathrm{Le}$-Cre-only control mice in addition to animals homozygous for the floxed allele but lacking the Le-Cre transgene. The independent ocular phenotypes resulting from the $\mathrm{Le}$-Cre transgene raise concerns about these previous studies that failed to include $\mathrm{Le}$-Cre controls. $F V B / \mathrm{N}$ inbred mice provided the original genetic background for the Le-Cre transgene, and hemizygous Le-Cre transgenics on this background typically appear identical to non-transgenic $F V B / N$ mice. However, the Le-Cre transgene, even in hemizygous state, may sensitize the lens in such a way as to exacerbate the phenotype resulting from simple loss of the floxed DNA segment under investigation. In this case, the Le-Cre transgene may actively enhance the phenotype rather than solely mediating the homozygous mutation. These concerns motivate the search for an alternative transgene to mediate gene deletions in the early developing lens or, at minimum, indicate the need for additional controls in the case of $\mathrm{Le}$-Cre.

Given the available CRE transgenic lines, the P0-3.9GFPCre transgenic mice represent the most likely replacement for the $\mathrm{Le}$-Cre mice, since both of these lines utilize the Pax6 P0 promoter that leads to CRE expression in the lens placode. The P0-3.9GFPCre mice have no reported ocular abnormalities in hemizygous or homozygous state. However, few studies have utilized the P0-3.9GFPCre transgenic mouse line and no comprehensive analysis of its tissue-specific CRE expression pattern exists. Here, we compare expression data for Le-Cre and P0-3.9GFPCre mice. Although the P0-3.9GFPCre lack the ocular defects sometimes seen in Le-Cre mice, we show widespread CRE expression in P0-3.9GFPCre mice prior to E8.0 that leads to floxed gene deletion in multiple, non-ocular tissues.

\section{Results}

In contrast to $\mathrm{Le}$-Cre mice, no obvious ocular abnormalities appear in homozygous P0-3.9GFPCre mice. Both the Le-Cre mice and P0-3.9GFPCre mice originated on an $F V B / N$ genetic background, and neither of these transgenic lines produce animals with conspicuous ocular abnormalities on this genetic background in hemizygous state. However, while the eyes from homozygous P0-3.9GFPCre mice appear normal, Le-Cre homozygous transgenic mice consistently exhibit smaller eyes and lenses with varying degrees of lens size reduction, fiber cell disorganization, and cataracts on all inbred and mixed genetic backgrounds tested, including $F V B / N$ (Fig. 2).

Real-time transgene expression and lineage tracing data provide different views of CRE expression during development. Since both the Le-Cre and PO-3.9GFPCre transgenes co-express CRE and GFP (green fluorescent protein), green fluorescence provides an excellent, easily visualized way to compare the real-time expression pattern of these transgenes during embryonic development. Nevertheless, real-time analysis fails to reveal CRE expression that may have occurred at an earlier developmental time point. A number of CRE-reporter mice exist that provide information about the cellular descendants of cells in which CRE expression occurs at any time during development. In particular, the original $G t$ (ROSA) 26Sor ${ }^{\text {tmiSor }}$ (R26R) transgenic mice possess a ubiquitously active promoter separated from a lac $Z$ gene by a floxed $p g k$-neo-polyA antibiotic resistance cassette [32]. CRE-mediated deletion of the neo cassette results in lacZ expression, visualized by $\mathrm{X}-\mathrm{Gal}$ histochemistry, in all cellular descendants, irrespective of whether CRE expression persists.

Real-time analysis, based on GFP fluorescence, revealed similar patterns of transgene expression in $\mathrm{Le}-\mathrm{Cre}$ and P0-3.9GFPCre transgenic embryos at E9.5, E10.5, E12.5, and E15.5 (Fig. 3). At E9.5, both lines exhibited obvious GFP expression in the head surface ectoderm surrounding and including the lens placode. GFP expression in both lines became more restricted to the lens and pancreas at E10.5, while a thin line of GFP expression in the apical ectodermal ridge of the forelimb 
Table 1 Comparison of published CRE transgenic lines with lens expression

\begin{tabular}{|c|c|c|c|c|c|c|c|}
\hline Name & Promoter elements & $\begin{array}{l}\text { Method of } \\
\text { creation }\end{array}$ & Lens expression & Non-lens expression & Status & $\begin{array}{l}\text { Coding } \\
\text { sequences }\end{array}$ & Notes \\
\hline $\begin{array}{l}\text { Ap2a- } \\
\text { IRESCre }\end{array}$ & $\begin{array}{l}\text { Endogenous mouse } \\
\text { Tcfap2a gene }\end{array}$ & $\begin{array}{l}\text { Embryonic } \\
\text { stem cell } \\
\text { targeted } \\
\text { mutation }\end{array}$ & $\begin{array}{l}\text { Head surface } \\
\text { ectoderm prior } \\
\text { to lens placode } \\
\text { formation (before } \\
\text { E9.0) }\end{array}$ & $\begin{array}{l}\text { Extensive head and } \\
\text { trunk surface ectoderm } \\
\text { and neural crest cells }\end{array}$ & Available & CRE & $\begin{array}{l}\text { IRES-CRE targeted to the } \\
\text { 3' UTR of the Tcfap2a } \\
\text { gene }\end{array}$ \\
\hline Le-Cre & $\begin{array}{l}6.5 \mathrm{~Kb} \text { mouse Pax6 P0 } \\
\text { promoter including both } \\
\text { the ectodermal enhancer } \\
\text { and retina/pancreas } \\
\text { enhancer. Approximately } \\
400 \text { bp mouse Pax6 } \\
\text { sequence follows the } \\
\text { GFP coding sequence }\end{array}$ & $\begin{array}{l}\text { Zygote } \\
\text { microinjection }\end{array}$ & $\begin{array}{l}\text { Lens placode } \\
\text { and surrounding } \\
\text { surface ectoderm } \\
\text { by E9.5 with } \\
\text { expression } \\
\text { continuing in } \\
\text { lens epithelium }\end{array}$ & $\begin{array}{l}\text { Endocrine pancreas, all } \\
\text { surface ectoderm- } \\
\text { derived eye structures, } \\
\text { epidermis from eye to } \\
\text { snout }\end{array}$ & Available & $\begin{array}{l}\text { CRE and } \\
\text { GFP }\end{array}$ & $\begin{array}{l}\text { Nuclear-localized CRE } \\
\text { separated from GFP by } \\
\text { an IRES. Microphthalmia } \\
\text { in homozygotes and } \\
\text { genetic background- } \\
\text { dependent variable ocu- } \\
\text { lar abnormalities in } \\
\text { hemizygotes }\end{array}$ \\
\hline LR-Cre & $\begin{array}{l}\text { Three tandem copies of } \\
\text { the mouse Pax } 6 \text { P0 } \\
\text { ectodermal enhancer } \\
\text { upstream of the minimal } \\
\text { P0 promoter }\end{array}$ & $\begin{array}{l}\text { Zygote } \\
\text { microinjection }\end{array}$ & $\begin{array}{l}\text { Lens placode } \\
\text { and surrounding } \\
\text { surface ectoderm } \\
\text { by E9.5 }\end{array}$ & Optic vesicle by E9.5 & Available & $\begin{array}{l}\text { CRE and } \\
\text { GFP }\end{array}$ & $\begin{array}{l}\text { CRE separated from GFP } \\
\text { by an IRES }\end{array}$ \\
\hline MLR10 & $\begin{array}{l}366 \text { bp mouse aA- } \\
\text { crystallin promoter with } \\
\text { an internal insertion of a } \\
20 \text { bp Pax } 6 \text { consensus } \\
\text { binding site }\end{array}$ & $\begin{array}{l}\text { Zygote } \\
\text { microinjection }\end{array}$ & $\begin{array}{l}\text { Lens vesicle by } \\
\text { E10.5-11 }\end{array}$ & $\begin{array}{l}\text { Snout and vibrissae } \\
\text { follicles, as well as in } \\
\text { parts of the midbrain } \\
\text { and pituitary gland by } \\
\text { E12.5 }\end{array}$ & Available & CRE & \\
\hline MLR39 & $\begin{array}{l}366 \text { bp mouse aA- } \\
\text { crystallin promoter driv- } \\
\text { ing CRE with co-injected } \\
\text { Tyrosinase minigene }\end{array}$ & $\begin{array}{l}\text { Zygote } \\
\text { microinjection }\end{array}$ & $\begin{array}{l}\text { Lens fiber cells } \\
\text { by E12.5 }\end{array}$ & $\begin{array}{l}\text { Mosaic RPE expression } \\
\text { of CRE }\end{array}$ & Available & $\begin{array}{l}\text { CRE and } \\
\text { tyrosinase }\end{array}$ & $\begin{array}{l}\text { Co-injection of both the } \\
\text { CRE and tyrosinase } \\
\text { transgene resulted in } \\
\text { light coat and RPE } \\
\text { pigmentation. CRE } \\
\text { restricted to lens fibers } \\
\text { and RPE }\end{array}$ \\
\hline maA-Cre & $\begin{array}{l}366 \mathrm{bp} \text { mouse aA- } \\
\text { crystallin promoter }\end{array}$ & $\begin{array}{l}\text { Zygote } \\
\text { microinjection }\end{array}$ & $\begin{array}{l}\text { Assumed in lens } \\
\text { fiber cells by } \\
\text { E12.5 }\end{array}$ & Unknown & Extinct & CRE & $\begin{array}{l}\text { First demonstrated use of } \\
\text { CRE recombination in } \\
\text { transgenic mice }\end{array}$ \\
\hline Nes-Cre & $\begin{array}{l}\text { Approximately } 5 \mathrm{~kb} \text { rat } \\
\text { nestin promoter with } \\
\text { nestin nervous system- } \\
\text { specific enhancer follow- } \\
\text { ing the human growth } \\
\text { hormone poly adenyla- } \\
\text { tion signal }\end{array}$ & $\begin{array}{l}\text { Zygote } \\
\text { microinjection }\end{array}$ & $\begin{array}{l}\text { Lens epithelium } \\
\text { and fiber cells by } \\
\text { E14.5 }\end{array}$ & $\begin{array}{l}\text { Central and peripheral } \\
\text { nervous system, ciliary } \\
\text { body and isolated } \\
\text { expression in the heart } \\
\text { and kidney }\end{array}$ & Available & CRE & $\begin{array}{l}\text { Widespread non-lens ex- } \\
\text { pression including retina } \\
\text { and ciliary body within } \\
\text { the eye }\end{array}$ \\
\hline $\begin{array}{l}\text { PO- } \\
\text { 3.9GFPCre }\end{array}$ & $\begin{array}{l}3.9 \mathrm{~Kb} \text { mouse Pax6 P0 } \\
\text { promoter including both } \\
\text { the ectodermal enhancer } \\
\text { and retina/pancreas } \\
\text { enhancer }\end{array}$ & $\begin{array}{l}\text { Zygote } \\
\text { microinjection }\end{array}$ & $\begin{array}{l}\text { Lens placode } \\
\text { and surrounding } \\
\text { surface ectoderm } \\
\text { by E9.5 with } \\
\text { expression } \\
\text { continuing in } \\
\text { lens epithelium }\end{array}$ & $\begin{array}{l}\text { Endocrine pancreas, } \\
\text { stomach mesenchyme, } \\
\text { apical ectodermal ridge, } \\
\text { all surface ectoderm- } \\
\text { derived eye structures, } \\
\text { epidermis from eye to } \\
\text { snout }\end{array}$ & Available & $\begin{array}{l}\text { CRE and } \\
\text { GFP }\end{array}$ & $\begin{array}{l}\text { CRE and GFP are } \\
\text { expressed as a fusion } \\
\text { gene }\end{array}$ \\
\hline $\begin{array}{l}\text { Pax6(lens)- } \\
\text { Cre }\end{array}$ & $\begin{array}{l}\text { Minimal mouse P0 Pax6 } \\
\text { promoter preceded by a } \\
\text { single copy of the } 340 \mathrm{bp} \\
\text { ectodermal enhancer }\end{array}$ & $\begin{array}{l}\text { Zygote } \\
\text { microinjection }\end{array}$ & $\begin{array}{l}\text { Lens placode by } \\
\text { E9.5 }\end{array}$ & Unknown & Extinct & CRE & \\
\hline
\end{tabular}

appeared only in the P0-3.9GFPCre transgenic embryos. E12.5 and E15.5 embryos expressed externally visible GFP only in the eye with fluorescence intensity appearing stronger in the Le-Cre embryos than in the P0-3.9GFPCre embryos.

Despite the similar GFP expression patterns seen in both lines, lineage-tracing analysis, based on LacZ expression (visualized by $\mathrm{X}-\mathrm{Gal}$ ), revealed distinct differences between Le-Cre and P0-3.9GFPCre transgenic embryos. Blue X-Gal staining in the E9.5 Le-Cre embryos appeared in a bilateral swath of head surface ectoderm encompassing the lens placode, matching the GFP expression pattern at the same stage. However, $\mathrm{X}$-Gal staining appeared widespread in the E9.5 P0-3.9GFPCre embryos, with abundant expression in both the lens placode and the heart (Fig. 3). 


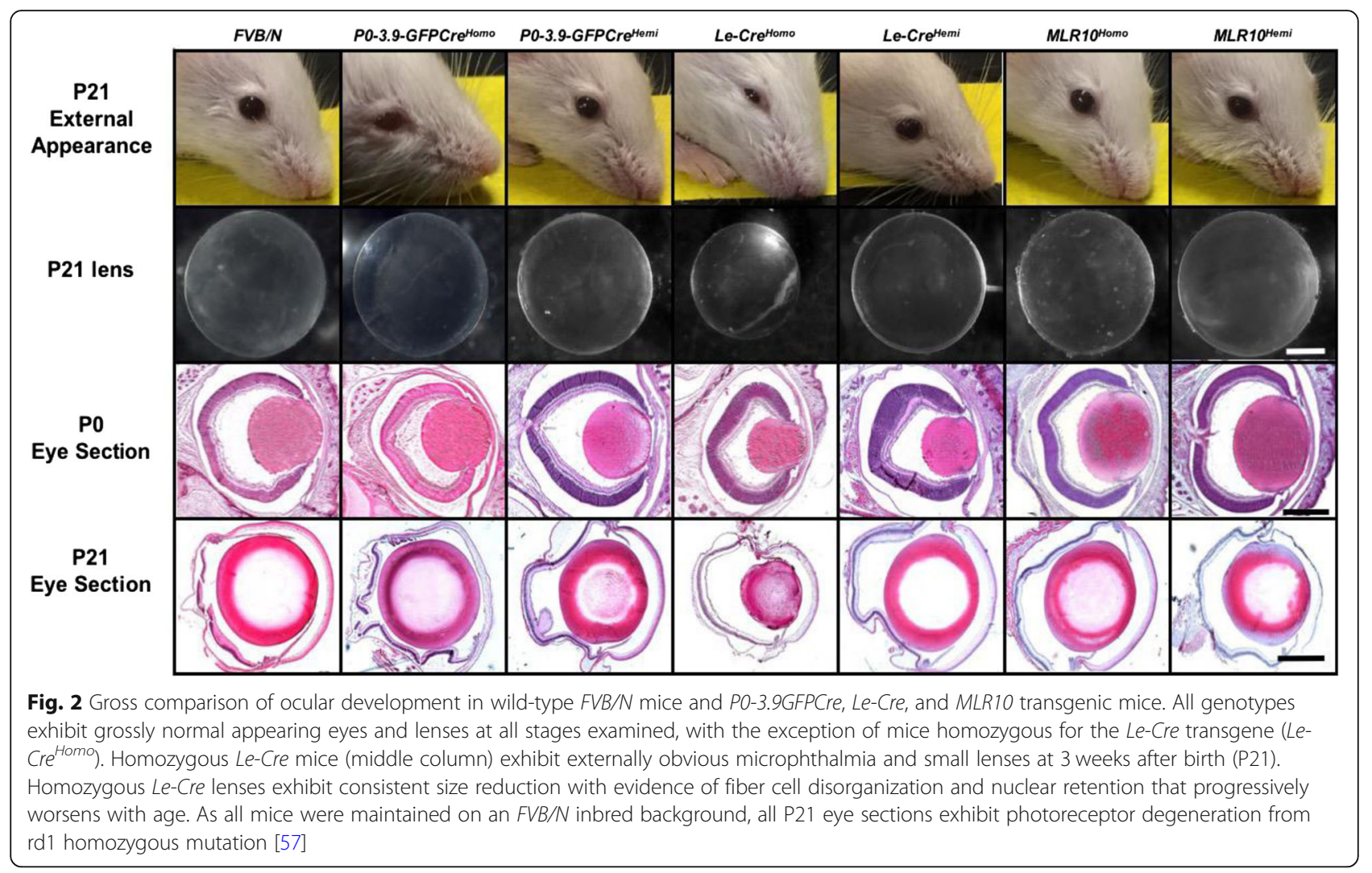

Lineage tracing revealed divergent expression patterns of CRE-mediated gene deletion between $\mathrm{Le}$-Cre and P0-3.9GFPCre embryos subsequent to lens formation. As development progressed beyond E9.5, Le-Cre lenses exhibited deep blue staining with the surrounding surface ectoderm appearing more lightly stained and forming a blue streak encompassing the eye and extending to the end of the snout (Fig. 3, X-Gal, Le-Cre E10.5-E15.5). By E15.5, closure of the developing eyelid obscured the blue staining within the lens. Elsewhere, X-Gal staining in the developing pancreas appeared through the translucent Le-Cre embryos at E9.5 and E10.5. Likewise, many Le-Cre embryos exhibited some X-Gal staining in the developing forebrain at E9.5-E10.5 (Fig. 3, asterisks). As the overlying tissues thickened in the $\mathrm{Le}$-Cre embryos, the internal X-Gal staining in the pancreas and forebrain faded from view (Fig. 3, X-Gal, Le-Cre E12.5, E15.5). Although P0-3.9GFPCre embryos exhibited considerable embryo-to-embryo variability, most E10.5E15.5 embryos exhibited extensive, mosaic X-Gal staining throughout the entire embryo surface (Fig. 3, bottom row).

Sections through the developing eye localized the $\mathrm{X}$-Gal staining in the Le-Cre embryos exclusively in the lens placode at E9.5 and in the developing lens and ocular surface ectoderm derivatives (corneal epithelium, developing conjunctiva, and eyelid surface) from E10.5-
E15.5 (Fig. 4). Sections through P0-3.9GFPCre embryo heads revealed a similar pattern of X-Gal staining at E9.5 and E10.5. Alternatively, P0-3.9GFPCre eyes often exhibited patchy X-Gal staining in the retina (see Fig. 4, E12.5, asterisk) and more extensive surface ectoderm staining than seen in the Le-Cre embryos (see Fig. 4, E15.5).

To investigate the origin of the divergent X-Gal staining pattern observed between $\mathrm{Le}$-Cre and P0-3.9GFPCre embryos, we examined embryos from each strain at E8.5 (Fig. 5). At this stage, weak X-Gal staining in $\mathrm{Le}$-Cre embryos appeared only in the developing pancreas. In contrast, the E8.5 P0-3.9GFPCre embryos exhibited an extensive speckled pattern of X-Gal staining throughout much of the embryo with a relatively greater concentration of stained cells visible in the area of the developing heart. This early mosaic pattern of CRE expression in P0-3.9GFPCre embryos, prior to E9.0, is consistent with the extensive non-ocular X-Gal staining pattern seen in older embryos.

Immunohistochemistry, using an antibody to CRE, provided a more direct assessment of CRE expression in the eyes of Le-Cre and P0-3.9GFPCre embryos (Fig. 6). Comparisons were made between hemizygous and homozygous E15.5 eyes from both Le-Cre and P0-3.9GFPCre embryos with non-transgenic $F V B / N$ and homozygous MLR10 transgenic eyes providing negative 


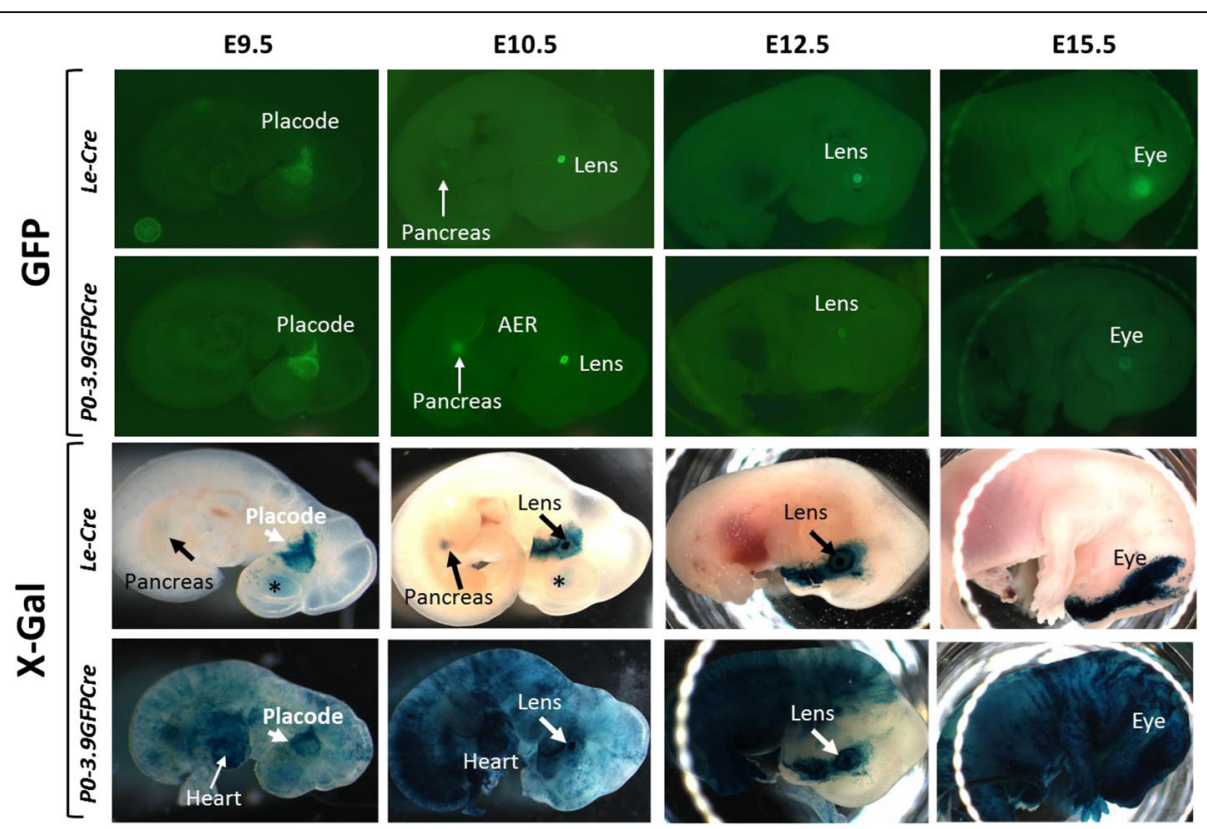

Fig. 3 Comparison of Le-Cre and P0-3.9GFPCre embryos using both real-time transgene expression and lineage tracing. GFP (top two rows) COexpressed with the CRE transgene in both Le-Cre and P0-3.9GFPCre mice made it possible to compare real-time transgene expression of both transgenes in whole mount embryos. X-Gal staining (bottom two rows) in embryos carrying both the ROSA26 CRE reporter (Gt(ROSA)26Sor ${ }^{\text {tm } 1 \text { Sor) }}$ ) and either the Le-Cre or P0-3.9GFPCre transgene provided an alternate way to compare the CRE transgenic lines based on lineage tracing of CRE expressing cells. Le-Cre (first row) and P0-3.9GFPCre (second row) transgenic embryos exhibit largely identical GFP expression patterns from E9.5 through E15.5 with the exception of expression in the apical ectodermal ridge (AER) of the forelimb observed specifically in the P0-3.9GFPCre transgenic embryos at E10.5. In contrast to the largely identical pattern of GFP expression, X-Gal staining revealed marked differences in expression between the Le-Cre (third row) and P0-3.9GFPCre (fourth row) transgenic embryos. Although P0-3.9GFPCre exhibited extensive embryoto-embryo variability, all embryos from this strain exhibited extensive non-ocular X-Gal staining patterns at every stage examined. Externally visible X-Gal staining in the Le-Cre embryos remained restricted to the eye and surface ectoderm surrounding the eye proceeding in a streak of ectoderm toward the developing snout and the pancreas. Some X-Gal staining in the forebrain showed through the surface ectoderm at E9.5 and E10.5 in Le-Cre embryos (asterisks)

and positive controls for CRE expression, respectively. Homozygous $\mathrm{Le}$-Cre mice uniquely exhibit reduced lens size, despite both Le-Cre and P0-3.9GFPCre mice exhibiting a similar CRE expression pattern in both the lens epithelium and in the corneal epithelium. CRE expression appeared in the developing neural retina in both
Le-Cre and P0-3.9GFPCre eyes (Fig. 6, arrows). The CRE positive nuclei in the $\mathrm{Le}$-Cre retina formed a reasonably tight layer in the middle of the posterior half of the retina. In the P0-3.9GFPCre retina, CRE positive nuclei appeared more dispersed throughout the thickness of the posterior half of the retina. In both strains, CRE

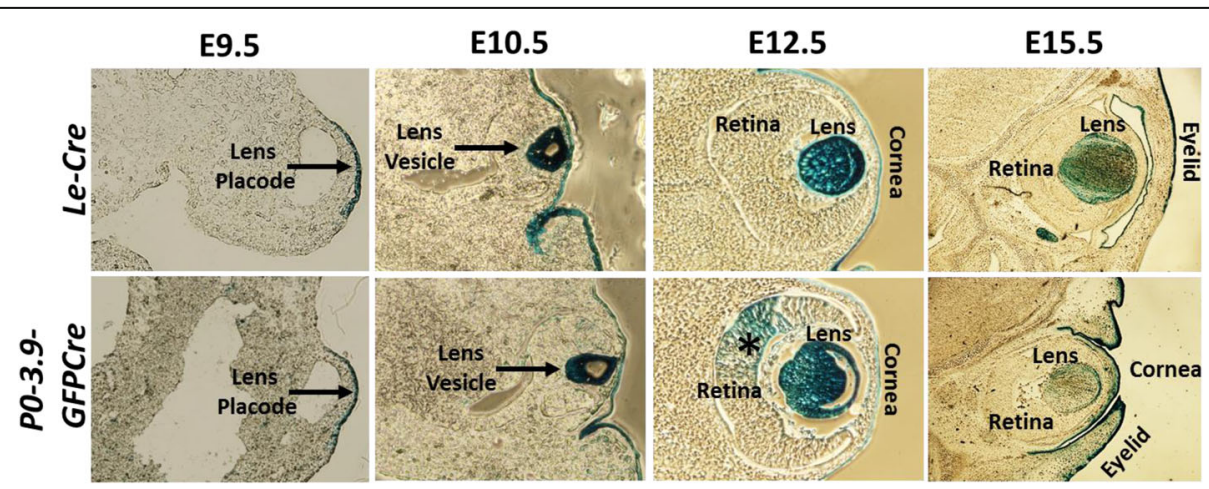

Fig. 4 Comparison of X-Gal staining patterns in Le-Cre and PO-3.9GFPCre eye sections. Although the ocular pattern of blue X-Gal staining appeared similar in Le-Cre (top row) and P0-3.9GFPCre (bottom row) embryos, patchy retinal X-Gal staining only appeared in P0-3.9GFPCre embryos (asterisk at E12.5) 


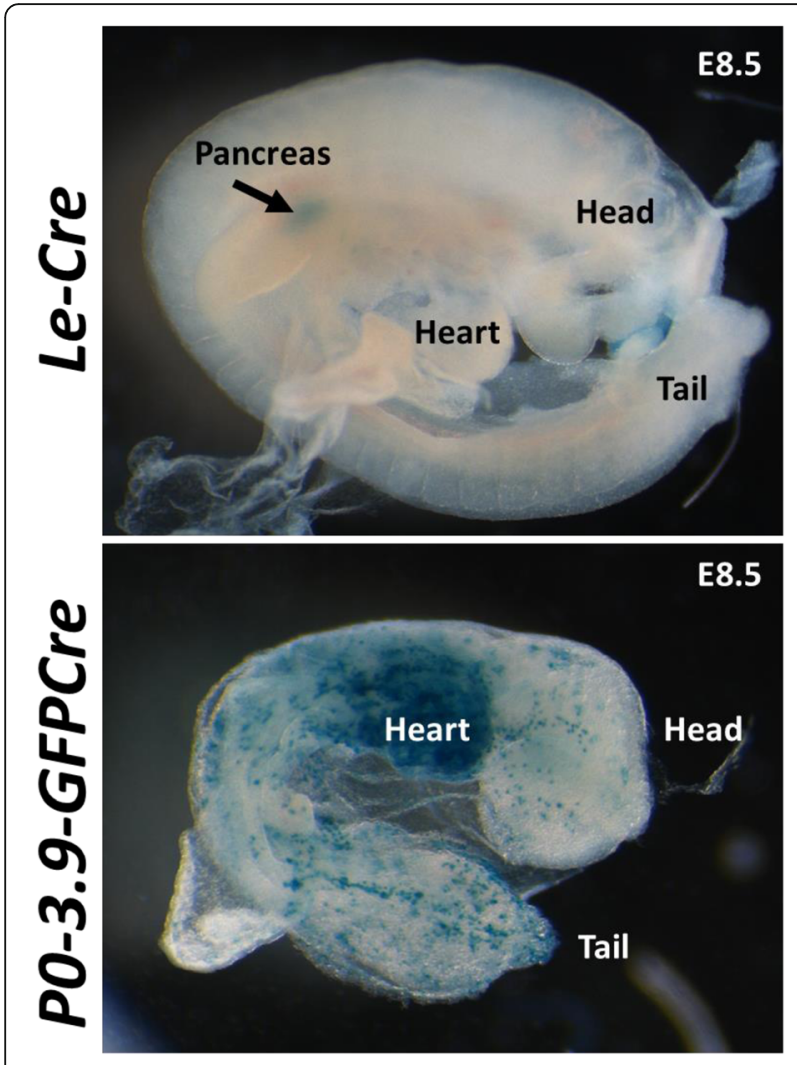

Fig. 5 P0-3.9GFPCre E8.5 embryos exhibit extensive CRE-mediated recombination prior to lens placode formation. At E8.5, X-Gal staining in Le-Cre embryos (top) remained restricted to the developing pancreas. In contrast, P0-3.9GFPCre embryos (bottom) exhibited many patches of X-Gal stained tissue throughout the embryo, with particularly high numbers of blue clones in the developing heart region

expression in the retina appeared stronger in the homozygous transgenic embryos. These cells are likely postmitotic because they appear restricted to the developing inner nuclear layer. For comparison, MLR10 mice exhibit normal ocular size with CRE protein expression most prominent in the elongating lens fiber cells at E15.5, with no ocular CRE expression outside the lens.

Although the extra-ocular CRE expression pattern of Le-Cre and P0-3.9GFPCre mice differed substantially, the patterns within the lens appeared similar. At E15.5, the lens expression pattern of MLR10 mice appeared largely reciprocal to that of the other two CRE transgenic strains. Le-Cre and P0-3.9GFPCre expression appeared in the epithelium with no evidence of fiber cell CRE expression while the CRE protein in the MLR10 mice appeared exclusively in the nuclei of differentiating fiber cells. Despite the lack of CRE protein in the MLR10 E15.5 lens epithelium, MLR10 mice do express CRE in the lens epithelial precursors at an earlier stage of development [8].

Given the similar lens expression pattern of the Le-Cre and P0-3.9GFPCre mice, we conducted further analyses in an attempt to explain why ocular abnormalities occur in all Le-Cre homozygotes and some Le-Cre hemizygotes [30]. The microphthalmia seen in homozygous Le-Cre mice could arise via insertional mutation if transgene sequences disrupt gene coding sequences or cis-regulatory elements. We used fluorescence in situ hybridization (FISH) to localize the Le-Cre transgene sequences to mouse chromosome 16 , nearby and telomeric to a BAC clone DN-4E11 (Fig. 7). The Le-Cre strain in use today represents one of two founder lines produced via microinjection of the identical construct into $F V B / N$ zygotes [9]. Homozygous transgenic mice derived from a second founder also developed microphthalmia (Dr. Ruth Ashery-Padan-unpublished data). The line established from the second founder (RD6) is extinct, but fibroblasts established from the last surviving mouse from this line were used for FISH to establish that the insertion site for this transgene was on chromosome 10, based on co-hybridization with BAC clone RP24-257H11 (Additional file 1: Figure S1). The similar homozygous phenotype of two independent transgenic lines derived by inserting the same microinjection construct into two different loci makes it unlikely that microphthalmia in both Le-Cre transgenic lines results from independent insertional mutations.

Because overexpression of CRE can induce toxicity in some cell types [33-37], we quantitatively examined CRE RNA expression in newborn hemizygous Le-Cre and P0-3.9GFPCre lenses. RNA-Seq analysis of whole newborn lenses showed a significantly higher expression (approximately fourfold normalized reads) of CRE transcripts in the Le-Cre lenses than the P0-3.9GFPCre lenses (Fig. 8a). To explore this result further, we measured CRE transcripts in newborn lenses from hemizygous Le-Cre, P0-3.9GFPCre, and MLR10 mice by RT-qPCR. In addition, we analyzed RNA from dissected lens fiber cells and cells adherent to the lens capsule (enriched for lens epithelial cells). The MLR10 lens RNA samples contained approximately 7 -fold and 35-fold more CRE transcripts than whole lens RNA samples from Le-Cre and P0-3.9GFPCre lenses, respectively (Fig. 8b). As expected, both the Le-Cre and P0-3.9GFPCre lenses contained more CRE transcripts in the epithelial cell RNA fraction than in the fiber cell RNA fraction. Despite this, the RT-qPCR analysis revealed no significant difference between CRE transcript abundance derived from fiber cell and epithelial cell RNA fractions from MLR10 lenses.

To determine if the larger number of CRE transcripts in the Le-Cre lenses relative to the P0-3.9GFPCre lenses correlated with an increased abundance of CRE protein, we performed western blot analysis on newborn lenses using a specific CRE antibody (Fig. 8c). As expected, the CRE immunoreactive band from the Le-Cre lenses appeared 


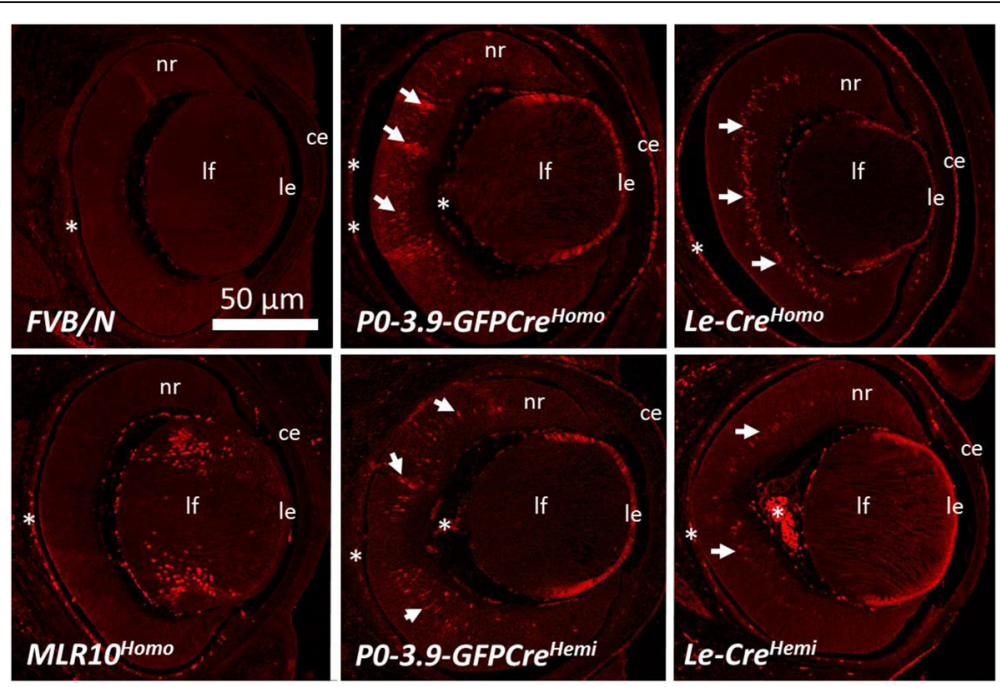

Fig. 6 Immunohistochemical detection of CRE protein in P0-3.9GFPCre, Le-Cre, and MLR10 transgenic mice at E15.5. MLR10 exhibited CRE protein expression specifically in the nuclei of differentiating lens fiber cells (If) within the eye at E15.5, while P0-3.9GFPCre, Le-Cre lenses showed obvious CRE protein in the epithelium of both the lens (le) and cornea (ce) and numerous cells within the developing neural retina (nr) indicated by arrows. Notice that the homozygous Le-Cre (Le-Cre ${ }^{\mathrm{Homo}}$ ) lens is specifically small and misshapen relative to the lenses from the other genotypes. The FVB/N lens exhibits no specific staining with the anti-CRE antibody and serves as a negative control. Autofluorescence in blood cells in the choroid and tunica vasculosa lentis represent non-specific signal (asterisks). Transgenic homozygotes and hemizygotes are indicated by homo and hemi, respectively

lower $(37 \mathrm{kDa})$ than the band from GFP-CRE fusion protein expressed by the P0-3.9GFPCre lenses (60 kDa). Quantitative analysis of the relative signal intensity of the CRE immunoreactive band to the GAPDH immunoreactive loading control revealed that newborn $\mathrm{Le}$-Cre lenses expressed approximately twice the amount of CRE protein than newborn P0-3.9GFPCre lenses (Fig. 8c). No CRE immunoreactivity was observed in $F V B / N$ lens protein.
Given the phenotypic differences between $\mathrm{Le}$-Cre and P0-3.9GFPCre homozygous lenses, we sought to determine if other genes were differentially expressed in hemizygous lenses from these strains, relative to non-transgenic $F V B / N$ lenses. Relative to the $F V B / N$ background strain, hemizygous P0-3.9GFPCre lenses only showed significant upregulation of two genes, including CRE and downregulation of one gene (Fig. 9). In

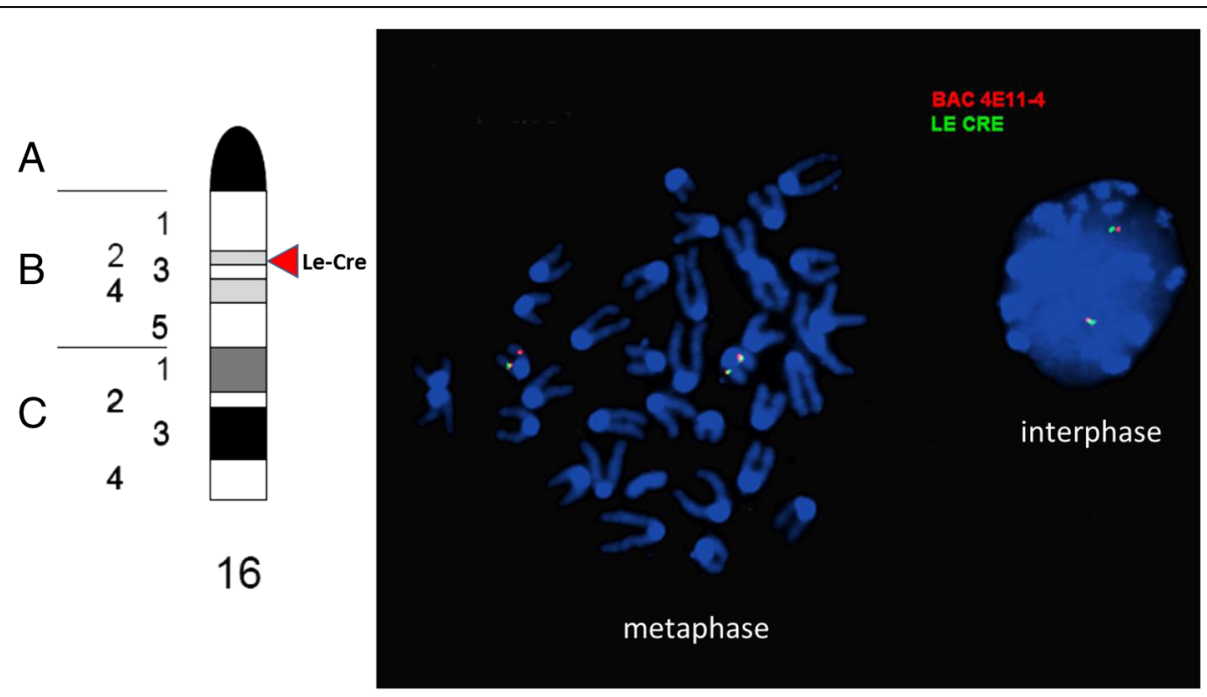

Fig. 7 Fluorescence in situ hybridization (FISH) localization of the Le-Cre transgene to chromosome 16. Co-localization of fluorescently labeled DNA probes for both CRE (green signal) and BAC DN-4E11, a mouse BAC from chromosome 16 (red signal) confirmed the chromosomal location of the Le-Cre transgene insertion. The approximate cytogenetic location of the Le-Cre transgene is indicated by a red arrowhead on the mouse chromosome 16 idiogram (from the Idiogram Album by David Adler@ 1994) on the left side of the figure 

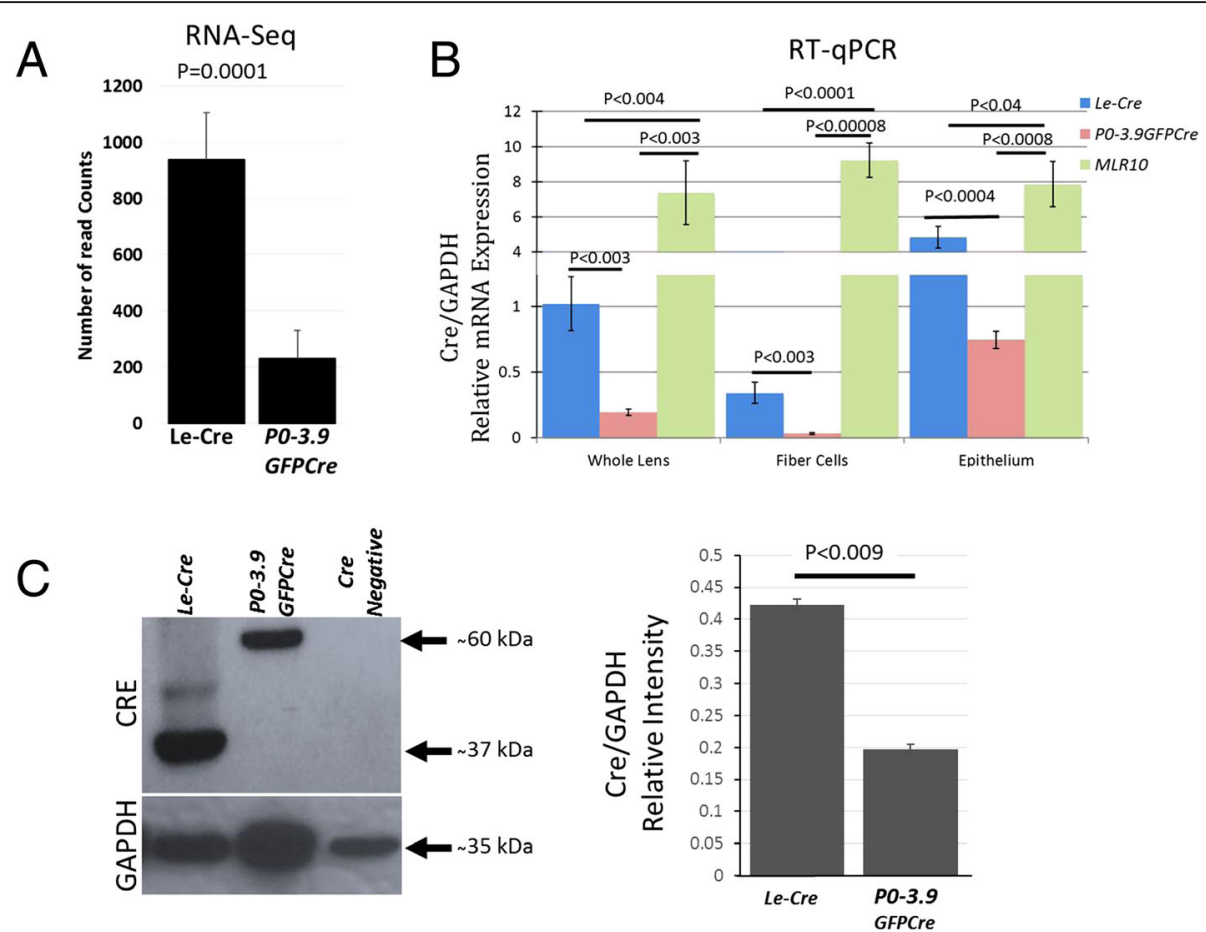

Fig. 8 Cre expression in Le-Cre and P0-3.9GFPCre lenses. RNA-Seq analysis detected significantly more CRE reads in newborn lens RNA from the Le-Cre mice than from P0-3.9GFPCre mice (a). Quantitative RT-PCR analysis confirmed the increase in CRE mRNA in newborn Le-Cre lenses relative to P0-3.9GFPCre lenses (b). Western blots revealed that newborn Le-Cre lenses also expressed relatively more CRE protein than P0-3.9GFPCre lenses (c, blot). Image-J analysis showed that, relative to GAPDH, the Le-Cre lenses expressed nearly twice as much CRE protein as the P0-3.9GFPCre lenses (c, graph). Error bars indicate standard error of the mean calculated by a two-tailed Student's $t$ test. Each bar in this figure represents the average of three biological replicates and three technical replicates

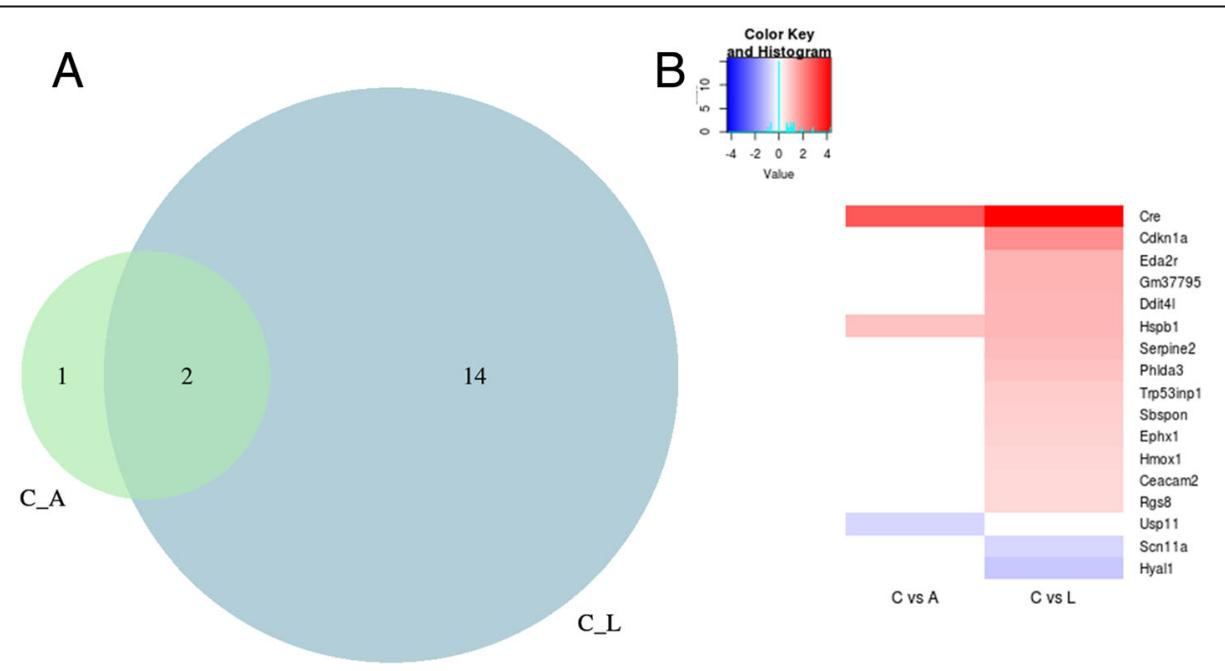

Fig. 9 Differential gene expression in hemizygous newborn Le-Cre and P0-3.9GFPCre lenses. The expression of transcripts expressed in newborn Le-Cre and P0-3.9GFPCre lenses were compared to newborn lens transcripts from the background FVB/N strain mice by RNA-Seq analysis. A Venn diagram (a) illustrates the total number of genes differentially expressed by the transgenic lenses versus the FVB/N lenses while the heatmap (b) lists all of the transcripts differentially expressed with red indicating overexpression and blue indicating underexpression. The Le-Cre lenses differentially expressed 16 genes while the P0-3.9GFPCre lenses differentially expressed only three genes. Both transgenic lenses overexpressed CRE and Hspb1 transcripts. The P0-3.9GFPCre lenses uniquely underexpressed Usp11. Many of the overexpressed transcripts in the Le-Cre lenses (Cdkn1a, Hmox1, Phlda3, and Trp53inp1) are associated with apoptosis and/or stress response (Hspb1, Ephx1) 
contrast, the hemizygous $\mathrm{Le}$-Cre lenses significantly upregulated 14 genes and downregulated two genes. Although neither CRE nor GFP is expressed in $F V B / N$ lenses, we specifically measured CRE expression relative to GAPDH in all three lines but did not measure GFP expression.

Although neither transgenic line differentially expressed many genes in the hemizygous lens, the Le-Cre lenses differentially expressed more than five times the number of genes than seen in the P0-3.9GFPCre lenses. Transgenic lenses from both lines overexpressed $H s p b 1$ transcripts relative to $F V B / N$ lenses. Hspb1 encodes a small heat shock protein (HSP25 in mouse/HSP27 in humans) [38] that acts as stress-induced chaperone involved in the regulation of cell cycle arrest, cell differentiation, and apoptosis [39]. RNA-Seq analysis from newborn lens RNA revealed that the $\mathrm{Le}$-Cre lenses specifically upregulated several genes associated with apoptosis or cell growth. These include Cdkn1a, Hmox1, Phlda3, Serpine2, and Trp53inp1. Of these deregulated transcripts, Cdkn1a exhibits the highest overexpression. The Cdkn1a gene encodes the cyclin-dependent kinase inhibitor, p21 ${ }^{\text {Cip1 }}$, a potent cell cycle inhibitor and target for p53-mediated apoptosis [40]. Downregulated genes included Usp11 for P0-3.9GFPCre and Scn11a and Hyal1 for Le-Cre. USP11 acts as a deubiquitylase that can stabilize a number of protein substrates including p53 [41] and p21 ${ }^{\mathrm{CIP} 1}$ [42]. Scn11A encodes a voltage-gated sodium channel protein (Nav1.9) that is preferentially expressed in sensory neurons and associated with pain perception [43]. Hyal1 encodes a hyaluronidase implicated in extracellular matrix degradation and epithelial-mesenchymal transition [44]. Notably, none of the genes encoding important transcription factors involved in lens development ( $\mathrm{Pax6}$, Six3, c-Maf, Pitx3, Hes1, Prox1, Hsf4, Sox2, Sox1, etc.) [45] are deregulated in the lenses of either transgenic line. Significant gene ontology (GO) terms for the differentially expressed genes in the Le-Cre and P0-3.9GFPCre lenses are listed in Table 2.

\section{Discussion}

Cre recombinase provides an important tool for genome manipulation. This remains true in studies of lens development and physiology, the system that first demonstrated the utility of CRE in transgenic mice. Precisely, how to deliver CRE to the lens is a relevant issue in any experimental context. The currently available transgenic strains each have advantages and disadvantages that merit consideration prior to conducting experiments in living animals.

Of the transgenic lines that express CRE in the lens, the Le-Cre and MLR10 lines have proven most popular. Lenses from homozygous MLR10 mice appear normal, suggesting a lack of CRE-toxicity. Ocular CRE expression within MLR10 mice only occurs in the lens, but this line does not express CRE in the lens placode and may exhibit incomplete recombination in the lens epithelium with some floxed alleles. Alternatively, the Le-Cre transgenic mice exhibit excellent recombination of floxed alleles in the lens placode resulting in floxed allele deletion in the lens, corneal epithelium, conjunctiva, lacrimal glands, and eyelids. Nevertheless, CRE expression in $\mathrm{Le}$-Cre mice also recombines floxed alleles in the endocrine pancreas. Our detection of CRE immunoreactivity in the developing retina of both Le-Cre and P0-3.9GFPCre mice (Fig. 6) suggests that floxed allele deletion occurs in a subset of the retina in these mice as well. Curiously, at E15.5, we did not detect CRE-mediated recombination in the $\mathrm{Le}$-Cre retina using CRE reporter transgenes (Fig. 4). This might represent a delay between the onset of retinal CRE expression and having enough Lac $\mathrm{Z}$ protein expressed to show up in the $\mathrm{X}$-Gal reporter assay. The CRE expressing cells in the retina, based on their number and location (Fig. 6), are likely precursors of a subset of amacrine

Table 2 Gene ontology terms associated with differentially regulated genes in Le-Cre lenses

\begin{tabular}{|c|c|c|c|}
\hline GO term & Count & $p$ value & Genes \\
\hline Negative regulation of cell proliferation & 4 & $3.6 \times 10^{-3}$ & Cdkn1a, Hmox1, Serpine2, Trp53inp1 \\
\hline Negative regulation of cell growth & 3 & $4.7 \times 10^{-3}$ & Cdkn1a, Hyal1, Serpine2 \\
\hline Cellular response to UV-B & 2 & $6.6 \times 10^{-3}$ & Cdknla, Hyall \\
\hline Intrinsic apoptotic signaling pathway in response to DNA damage by p53 class mediator & 2 & $2.5 \times 10^{-2}$ & Cdknla, Phlda3 \\
\hline Positive regulation of apoptotic process & 3 & $3.1 \times 10^{-2}$ & Hmox1, Phlda3, Trp53inp1 \\
\hline Cellular response to heat & 2 & $3.2 \times 10^{-2}$ & Cdkn1a, Hmoxi \\
\hline Negative regulation of signal transduction & 2 & $4.3 \times 10^{-2}$ & Ddit4l, Rgs8 \\
\hline Cell cycle arrest & 2 & $6.5 \times 10^{-2}$ & Cdkn1a, Trp53inp1 \\
\hline Response to toxic substance & 2 & $6.9 \times 10^{-2}$ & Cdkn1a, Ephx1 \\
\hline Apoptotic process & 3 & $7.9 \times 10^{-2}$ & Hmox1, Phlda3, Trp53inp1 \\
\hline Positive regulation of angiogenesis & 2 & $9.6 \times 10^{-2}$ & Hmox1, Hyal1 \\
\hline
\end{tabular}


interneurons and horizontal cell precursors, previously identified in fate mapping experiments using a $450 \mathrm{bp}$ enhancer fragment included in both the Le-Cre and P0-3.9GFPCre constructs [23].

The consistent ocular abnormalities seen in $\mathrm{Le}$-Cre homozygotes coupled with the genetic background-dependent ocular phenotypes in Le-Cre hemizygotes remain the most serious concern for the use of these mice. Although homozygous P0-3.9GFPCre mice appear healthy, fertile, and have phenotypically normal lenses, the widespread non-ocular CRE expression in early development makes these mice a problematic substitute for the Le-Cre strain. There clearly exists a need to recapture the CRE expression pattern of Le-Cre mice without the associated ocular phenotypes. The avoidance of CRE expression in the pancreas and retina would also improve the gene deletion specificity offered by Le-Cre mice.

In principle, three mechanisms may explain the Le-Cre-induced ocular abnormalities. These include (1) insertional mutagenesis, (2) the titration of a transcription factor endogenously activating Pax6 expression in the lens or surface ectoderm, and (3) CRE or GFP toxicity. The similar phenotypic abnormalities occurring in two independently derived transgenic founder lines with different transgene integration sites exclude the insertional mutation mechanism. Others have suggested that multiple copies of the Pax6 P0 promoter might effectively reduce transcription factors available to activate Pax6 in the developing lens [30]. In fact, overexpression of Pax6 suppressed ocular phenotypes associated with Le-Cre hemizygotes on a CBA-enriched genetic background [30]. However, a reduction in Pax6 or other essential lens transcription factors should result in decreased expression of dependent transcripts. RNA-Seq analysis of $\mathrm{Le}$-Cre hemizygous lenses failed to reveal any significant reduction of Pax6 transcripts, PAX6-responsive transcripts, or transcripts of any other genes associated with lens development. The reasonably few transcriptional changes seen in hemizygous $\mathrm{Le}$-Cre lenses include several genes associated with apoptosis and growth arrest. Given these observations, we suggest that the independent ocular phenotypes observed in $\mathrm{Le}$-Cre transgenic mice result from CRE and/or GFP toxicity.

Numerous studies have shown that high-level, continuous expression of Cre recombinase can induce genomic instability and/or cell death. Male sterility in transgenic mice where the Prm1 promoter drove CRE expression resulted from extensive chromosomal rearrangements in developing spermatids subsequent to the completion of meiosis II [37]. This phenotype exhibited complete penetrance in males and male offspring from five independent transgenic founders and required CRE enzyme activity. Likewise, CRE expression driven by the surfactant protein $C$ promoter induces apoptosis in lung epithelial cells [46], and CRE expression from the $\alpha M y H C$ promoter leads to cardiotoxicity in transgenic mice [34]. CRE expression in keratinocytes, driven by either the Keratin 5 or Keratin 14 promoter, induces genomic instability, activation of p53, and cell cycle defects leading to frequent endomitosis and tetraploidy [33]. Although most transgenic studies attempt to direct CRE expression with tissue-specific regulatory sequences, transgenic mice often express CRE in secondary, unintended locations making CRE-dependent physiological phenotypes difficult to interpret [35]. Strikingly, the induction of CRE expression alone effectively led to apoptotic lymphoma regression in p53 deficient mice, demonstrating that CRE-induced apoptosis does not require p53 activity [47]. The toxic effects of CRE in transgenic mice appear to result from illegitimate recombination and/or DNA damage, initiated by CRE enzymatic activity at pseudo-LoxP sites, which occur at a frequency of 1.2 per megabase in the mouse genome [48].

In addition to CRE, the $\mathrm{Le}$-Cre mice express GFP via an internal ribosome entry site (IRES) within the transgene construct [9] and GFP expression can also lead to toxicity. The most striking evidence for GFP-induced physiological phenotypes comes from studies of GFP expression in muscles [49-52]. Of four transgenic mouse lines made with GFP driven by the $\alpha M y H C$ promoter, mice from the two highest expressing lines developed lethal dilated cardiomyopathy [50]. GFP also interacts with the actin-binding site of myosin and interferes with muscle contraction [51, 52]. GFP expression can also lead to the activation of the immune system and increased oxidative stress [53]. However, ubiquitous GFP expression in many different transgenic lines without reported ocular phenotypes suggests that CRE expression is a more likely cause for the observed ocular defects in Le-Cre mice.

If the transgene-induced ocular phenotypes seen in $\mathrm{Le}$-Cre mice result from toxicity, why are the other transgenic mice that express CRE in the lens apparently free from these abnormalities? The P0-3.9GFPCre mice also express both CRE and GFP in the lens, but our analysis demonstrates that this line expresses a lower level of CRE expression, both at the transcript and protein level, than the Le-Cre mice. Curiously, homozygous MLR10 mice display none of the ocular abnormalities seen in virtually all homozygous $\mathrm{Le}$-Cre mice. Although the MLR10 mice do not express GFP, they exhibit higher CRE transcript expression in both the lens epithelium and lens fiber cells at birth than either Le-Cre or P0-3.9GFPCre mice (Fig. 8b). However, at E15, CRE protein appeared nearly absent from the lens epithelium in 
homozygous MLR10 mice (Fig. 6). This incongruity could result from inefficient translation of CRE transcripts in the lens epithelium, a perinatal increase in lens epithelial CRE expression, or contamination of the lens epithelial RNA sample with differentiating secondary fiber cell RNA in MLR10 transgenic mice. It is also possible that high expression of CRE protein at the lens placode stage has a uniquely deleterious effect on subsequent lens development, thus sparing MLR10 mice where CRE expression initiates later. In any case, it appears that continuous, high-level expression of CRE from the placode stage and in the lens epithelium may compromise lens development.

It is possible that an efficient system to deliver transient, drug-inducible CRE to lens cell nuclei may avoid the ocular phenotypes seen in the Le-Cre mice. In particular, the CRE-ER system where CRE remains in the cytoplasm in the absence of tamoxifen ligand [54] represents a potential to limit the ability of CRE to induce DNA damage. Shi and Bassnett demonstrated that tamoxifen can induce postnatal CRE-mediated recombination in the lens using both a widely expressing CRE-ER transgene and GFP CRE reporter transgene [55], but this strategy only demonstrated mosaic recombination in the lens epithelium. It remains possible that an appropriate lens-directed CRE-ER transgene could lead to widespread tamoxifen-inducible recombination in either the postnatal lens or in the lens placode dependent on the timing of drug administration. Other inducible systems may also work in the developing lens and avoid continuous CRE expression in the lens epithelium. In these cases, investigators will also have to control for drug administration in the analysis of resulting phenotypes.

\section{Conclusion}

Choosing the best option for CRE delivery in studies of the lens requires careful consideration of both the timing and the pattern of CRE expression. Here, we have provided an analysis based on the previously produced CRE transgenic mice that express CRE in the lens. While each of the existent CRE transgenic lines have unique properties that may be advantageous for a particular experiment, it remains imperative that any studies using these mice contain the appropriate controls. These controls must include the analysis of animals expressing CRE in the absence of targeted, floxed alleles. The omission of this control makes it difficult or impossible to determine if the observed phenotype truly represents the loss of a targeted gene or an independent, CRE-mediated effect.

\section{Methods}

\section{Experimental animals}

Inbred $F V B / N$ mice were purchased from Harlan Sprague Dawley. Mice were bred and maintained in the
Miami University Animal Facility. All experimental manipulations received approval from the Miami University Institutional Care and Use Committee and conformed to the ARVO Statement for the Use of Animals in Ophthalmic and Vision Research. Le-Cre (Tg(Pax6-cre, GFP)1Pgr) transgenic mice, on the original $F V B / N$ background [9], were obtained from Dr. Ruth Ashery-Pandan (Department of Human Molecular Genetics and Biochemistry, Sackler Faculty of Medicine, Tel Aviv University). P0-3.9GFPCre (Tg(Pax6-GFP/cre)1Rilm) transgenic mice [12] were originally produced by Dr. Richard Maas (Department of Medicine, Division of Genetics, Harvard University, Boston, MA), and obtained on an $F V B / N$ inbred background from Dr. Salil Lachke (Department of Biological Sciences, University of Delaware). MLR10 mice were produced on an $F V B / N$ background as described [8] and the ROSA26 Cre reporter strain, Gt(ROSA)26Sor ${ }^{\text {tm1Sor }}$, was obtained from The Jackson Laboratory (Bar Harbor, ME). Hemizygous Le-Cre, P0-3.9GFPCre, and MLR10 were generated by crossing homozygous mice with either $F V B / N$ or ROSA26 CRE reporter strains.

\section{Evaluation of Cre transgene expression}

Timed pregnancies were obtained from $\mathrm{Le}$-Cre and P0-3.9GFPCre mice crossed with the ROSA26 Cre reporter strain [32], with noon of the day of vaginal plug observation considered E0.5 days of embryogenesis. Embryos from embryonic days 7.5, 8.5, 9.5, 10.5, 12.5, 15.5, and the day of birth (P0) were collected for evaluation. Embryos were visualized for GFP expression (co-expressed with CRE in both the Le-Cre and P0-3.9GFPCre mice) under a SteREO Discovery.V12 microscope (Zeiss). A Zeiss AxioCam MRc5 with AxioVison Extended Focus module was used to obtain images with increased focus depth. To visualize LacZ expression, embryos were lightly fixed with phosphate buffered $4 \%$ paraformaldehyde (Fisher chemical, Germany Cat. No. O4042), washed three times in phosphate buffered saline (PBS), and incubated in the dark overnight at room temperature in an X-Gal staining solution $(40 \mathrm{mg} / \mathrm{ml}$ $\mathrm{X}-\mathrm{Gal}, 50 \mathrm{mM}$ potassium ferrocyanide, $50 \mathrm{mM}$ potassium ferricyanide, $10 \%$ deoxycholate/20\%NP4-, $1 \mathrm{M}$ $\mathrm{MgCl}_{2}$ in $\left.1 \times \mathrm{PBS}\right)$. The next day, the samples were rinsed in PBS and post-fixed with $10 \%$ neutral buffered formalin (Thermo Scientific, MI, USA Cat. No. 5725) overnight at room temperature while protected from light. Following three washes with PBS, embryos were either photographed in whole mount or incubated in the dark at $4{ }^{\circ} \mathrm{C}$ in increasing sucrose concentrations from $7.5 \%$ to $30 \%$ sucrose for $12 \mathrm{~h}$ each step. Tissues were then embedded in a $30 \%$ sucrose/OCT mixture at 1:2 ratio and frozen and cryosectioned at $12 \mu \mathrm{m}$ thickness. Embryonic heads were sectioned anterior-posterior in a horizontal 
plane to include the cornea, lens, and retina. To visualize internal LacZ expression, frozen sections were stained with X-Gal and post-fixed with paraformaldehyde before mounting.

\section{FISH analysis}

Bone marrow was aspirated from the femur of transgenic and wild-type mice and grown overnight in RPMI media supplemented with 15\% FBS, (Gibco BRL). Subsequently, cells were harvested according to standard cytogenetics methods and stored in Carnoy fixative (3:1, methanol:glacial acetic acid) at $-20^{\circ} \mathrm{C}$. The $\mathrm{BAC}$ probes were labeled with Spectrum Orange or Spectrum Green using a nick translation kit (Vysis, Downer Groves, IL) according to the manufacturer's recommendations. The reaction was carried out for $8 \mathrm{~h}$ at $15^{\circ} \mathrm{C}$ and stopped by heating the sample to $70^{\circ} \mathrm{C}$ for $10 \mathrm{~min}$. FISH was performed on freshly prepared slides. The DNA was combined with mouse Cot-1 DNA (Gibco BRL), ethanol precipitated, resuspended in Hybridization Buffer (Sigma, St. Louis, MO), and denatured. The probes were applied to previously denatured slides. The hybridization was carried out overnight at $37^{\circ} \mathrm{C}$ and slides were washed in $2 \times \mathrm{xSC} / 0.1 \% \mathrm{NP}-40$ for $5 \mathrm{~min}$ at $42{ }^{\circ} \mathrm{C}$. The signals were viewed with fluorescence microscope (Zeiss Axioscope 40) equipped with appropriate filters, and analyzed with the Applied Imaging System. Physical localization of the Le-Cre transgene to chromosome 16 was confirmed using probes derived from both Cre recombinase and the NOD/Mrk Tac GSS BAC clone DN-4E11. FISH analysis of the RD6 fibroblasts utilized a digoxigenin-labeled probe for CRE and a biotin-labeled probe for BAC RP24-257H11. Hybridization signals were visualized with red and green fluorescently labeled antibodies for digoxigenin and biotin, respectively.

\section{Routine histology}

P0 and P21 pups of homozygous and hemizygous Le-Cre, P0-3.9GFPCre, and MLR10 were collected, genotyped, imaged, fixed with $10 \%$ neutral buffered formalin, processed to paraffin embedded, and sectioned at $7 \mu \mathrm{m}$ thickness. The samples were sectioned in an anterior-posterior plane to include the cornea, lens, and retina. To avoid the lenses shattering, the wax block was kept wet during sectioning. Histological features were compared using standard hematoxylin and eosin $(\mathrm{H} \&$ E) staining methods.

\section{Evaluating CRE protein expression through immunohistochemistry}

E15.5 embryo heads were collected and fixed in 10\% neutral buffered formalin at room temperature overnight. Standard protocols were used to process and embed tissues in paraffin wax. Paraffin blocks were sectioned at $5 \mu \mathrm{m}$ onto slides. The slides were washed in xylene and alcohol to remove paraffin and rehydrate the tissue. Then, the protein antigens on the sections were retrieved as previously described [5]. The slides were blocked with $10 \%$ normal goat serum in PBST. The primary antibody for CRE was purchased from Cell signaling 12830 (USA) and used at a 1:100 dilution. The primary CRE antibody was detected using a goat anti-rabbit IgG secondary antibody conjugated to Alexa Fluor 488 fluorescent probe (1:500 dilution). The sections were counterstained with DAPI (Vector Labs H-1200, Burlingame, CA, USA).

\section{Evaluating CRE protein expression through western blot}

Lenses were dissected from newborn mice and homogenized in RIPA buffer $(50 \mathrm{mM}$ Tris $\mathrm{HCl} \mathrm{pH} 8,150 \mathrm{nM}$ $\mathrm{NaCl}, 1 \% \mathrm{NP} 40,0.5 \%$ sodium deoxycholate) with protease inhibitor (Sigma-Aldrich, St. Louis, MO, USA). Equal amount of protein lysates were separated by $1 \%$ SDS-contained $10 \%$ polyacrylamide gel electrophoresis (SDS-PAGE) then transferred to PVDF membrane. The blot was blocked in blocking solution containing 5\% non-fat dry milk in $0.1 \%$ PBST for $2 \mathrm{~h}$ at room temperature. Then, the blots were incubated at $4{ }^{\circ} \mathrm{C}$ overnight with either at $1 / 3000$ rabbit monoclonal anti-CRE antibody (Cell signaling 12830, Carlsbad, CA), or 1/1000 rabbit polyclonal anti-GAPDH antibody (Cell signaling 2118) diluted in blocking solution. The next day, the blots were washed with $0.1 \%$ PBST and then incubated with the goat anti-rabbit HRP-conjugated secondary antibodies (1:5000 in $0.1 \%$ TBST) for $1 \mathrm{~h}$. The Clarity $^{\text {tm }}$ Western ECL Substrate (Bio-Rad 1705061, Hercules, CA) and resultant AutoRadiography film (Fisher NC9556985, USA) were used for detection and image development. Finally, quantification of the proteins of interest was done relative to GAPDH using Image J software.

\section{Evaluating CRE expression level through whole transcriptome Illumina sequencing}

Newborn lenses from wild-type $F V B / N$, hemizygous Le-Cre, and hemizygous P0-3.9GFPCre mice were collected at $\mathrm{PO}$ and pooled into three biological replicates, each containing six lenses from three mice. Total RNA, including mRNA, was extracted using the mirVana mRNA isolation kit (AM1560, ThermoFisher) according to the manufacturer's recommendations. Total RNA samples with the RNA integrity number (RIN, Agilent 2100 Bioanalyzer) $\geq 8.0$ were used to prepare a library of template molecules suitable for subsequent sequencing on an Illumina (St. Louis, MO) HiSeq platform. Polyadenylated RNA was purified from the total RNA samples using Oligo dT conjugated magnetic beads and prepared for single-end sequencing according to the Illumina 
TruSeq RNA Sample Preparation Kit v3. The resultant library was sequenced for 50 cycles using the TruSeq SBS kit on an Illumina HiSeq 2000 system at the Genomics and Sequencing Core Laboratory at the University of Cincinnati. Approximately 29 million single-end sequence reads of $51 \mathrm{bp}$ per sample were generated, and these sequences were mapped back to the mouse genome assembly GRCm38 (mm10). Adapters and poor-quality regions were trimmed using Trimmomatic-0.36 software. Gene and isoform abundance was quantified using RSEM-1.3.0 software. Reads were mapped to the C57BL/6J reference genome using GSNAP software. Differential expression analysis was completed using DESeq2-1.10.1 software. For differential expression, we used a cutoff value of equal to or greater than 1.5-fold change with an adjusted $p$ value $\leq 0.05$.

\section{Real-time PCR}

Lenses were manually removed from the eye at $\mathrm{P} 0$ from hemizygous Le-Cre, P0-3.9GFPCre, and MLR10 transgenic lines. Whole lenses, epithelium, and fiber cells were separately pooled into three biological replicates each containing six lenses or six fractions from three mice for each transgenic line. For the epithelial cell fraction and fiber cell fraction, lenses were dissected following the procedure previously described [56]. Total RNA was isolated using the Mini Total RNA Kit for Tissue (IBI Scientific IB47302, Peosta, IA, USA) and reverse-transcribed using the SuperScript IV First-Strand Synthesis System (Invitrogen 18091050, Carlsbad, CA, USA) according to the manufacturer's recommendations. Each biological cDNA replicate was amplified by qPCR three times. Real-time quantitative PCR analysis was performed using the SYBR-Green GoTaq qPCR Master Mix (Promega A6001, Madison, WI, USA) on a CFX Connect - 96 well system (Bio Rad). The expression levels of individual genes were normalized to GAPDH mRNA levels and analyzed using the delta-delta $\mathrm{Ct}$ method (Applied Biosystems) with significant differences revealed by a two-tailed Student's $t$ test. The primer sequences used in the real-time PCR assays for murine GAPDH are GACGTGCCGCCTGGAGAAAC forward and AGCCCAAGATGCCCTTCAGT reverse. The primer sequences used for CRE are CCTGTTTTGCACGT TCACCG forward and ATGCTTCTGTCCGTTTGCCG reverse.

\section{Additional file}

Additional file 1: Figure S1. FISH analysis using a probe for CRE labeled in red and a mouse BAC probe (RP24-257H11) labeled in green. Mitotic chromosome spreads from fibroblasts established from the last living homozygous transgenic mouse from the second founder (RD6) created with the identical DNA construct that established the Le-Cre transgenic line. An idiogram of mouse chromosome 10 with the location of transgene insertion (green arrowhead) is shown on the idiogram at the left of the FISH image. White arrows point to the overlapping FISH signals on each of the copies of chromosome 10. The idiogram was taken from the Idiogram Album by David Adler (c) 1994. (PDF 235 kb)

\section{Abbreviations}

AER: Apical ectodermal ridge; ce: Corneal epithelium; CRE: Cre recombinase; E9.0: Embryonic day 9.0; FISH: Fluorescence in situ hybridization; floxed: LoxPflanked; GFP: Green fluorescent protein; GO: Gene ontology terms; H \& E: Hematoxylin and eosin; IRES: Internal ribosome entry site; le: Lens; Le$\mathrm{Cre}^{\mathrm{Hemi}}$ : Hemizygous Le-Cre; Le-Cre ${ }^{\mathrm{Homo}}$ : Homozygous Le-Cre; If: Lens fiber cells; maA-Cre: Mouse aA-crystallin promoter transgenic CRE; Nav1.9: Scn 11A encodes a voltage-gated sodium channel protein; nr: Neural retina; P0: Embryonic day 0; P21: 3 weeks after birth; RPE: Retinal pigmented epithelium; TAg: SV40 large tumor antigen

\section{Acknowledgements}

This work represents many years of effort and received input from many people. In particular, the authors would like to acknowledge Dr. Richard Maas as the original source for the P0-3.9GFPCre transgenic mice and Dr. Salil Lachke for providing these mice on an FVB/N inbred genetic background. We acknowledge Dr. Nyla A. Heerema and Jadwiga Labanowska from The Ohio State University James Cancer Center for performing the FISH analysis of the Le-Cre transgene insertion. We would also like to acknowledge a former graduate student Dr. Bhavani P. Madakashira (Miami University), Ying Yang (Columbus Children's Hospital) and former undergraduate students Nathaniel A. Walton (The Ohio State University) and Jordan Lesher (Miami University) for assistance with the initial identification and characterization of the homozygous Le-Cre phenotype, and current undergraduate student, Anna M. Porter (Miami University), for help with histological preparation. The library preparation and RNA-Sequencing was carried out at the Genomics, Epigenomics and Sequencing Core at the University of Cincinnati by Dr. Xiang Zhang under the direction of Dr. Shuk-mei Ho. Ideogram diagrams for mouse chromosomes 10 and 16 were reproduced from the Ideogram Album: Mouse@ 1994 David Adler (http://www.pathology.washington.edu/research/cytopages/idiograms/mouse/). Finally, we wish to thank Dr. Steven Bassnett (Ophthalmology and Visual Sciences, Washington University School of Medicine) and Dr. Melinda K. Duncan (Department of Biological Sciences, University of Delaware) for helpful discussions about homozygous and hemizygous Le-Cre phenotypes. This work was made possible from support provided by the National Eye Institute (R01 EY012995) to M.L.R.

\section{Funding}

This manuscript was supported by R01EY012995 from the National Eye Institute, awarded to M.L.R.

\section{Availability of data and materials}

All data contained in this manuscript will be freely available upon request from the corresponding author. All raw RNA-Seq data has been deposited in the NCBI Sequence Read Archive (SRA) under the GEO accession number GSE125108.

\section{Authors' contributions}

PTL performed the histological and immunohistological comparisons of the control, P0-39.GFPCre, Le-Cre, and MLR10 transgenic mice and conducted the western blot analysis for CRE protein in transgenic lenses. SLP collected newborn lenses and isolated RNA prior to performing RT-qPCR analysis to compare Le-Cre, P0-3.9GFPCre, and MLR10 lenses and lens fractions and also assisted with the analysis of RNA-Seq data, embryo collection, and immunohistochemistry. TVH collected newborn mouse lenses and prepared RNA for RNA-Seq analysis. JEP assisted with embryo collection and lineage tracing analysis of CRE transgenic mice. LL assisted with bioinformatics analysis of RNA-Seq data. CL assisted with bioinformatics analysis of RNA-Seq data. ASL assisted with writing and editing the manuscript. LMW assisted with mouse genotyping and with initial characterization of the Le-Cre homozygous phenotype. RAP provided data and fibroblasts concerning the second founder line (R6D) made with the DNA construct that gave rise to the Le-Cre strain and provided critical feedback during manuscript preparation. PKR assisted with the FISH analysis of the fibroblasts from $R 6 D$ transgenic mice 
and provided critical feedback during manuscript preparation. JES assisted with the FISH analysis of the fibroblasts from the R6D transgenic mice. OS assisted with the characterization and prepared fibroblasts from the R6D transgenic mice. SR produced the P0-3.9GFPCre mice in the laboratory of Dr. Richard Maas and provided critical feedback during manuscript preparation. NLB and TG assisted with mapping the location of the Le-Cre transgene insertion and provided critical feedback during manuscript preparation. MLR initiated and directed all aspects of data collection and wrote the manuscript. All authors read and approved the final manuscript.

\section{Ethics approval and consent to participate}

All experiments involving animals were approved by the Miami University Institutional Care and Use Committee

\section{Consent for publication}

Not applicable.

\section{Competing interests}

None of the authors have any financial or other competing interests concerning the information presented in this manuscript.

\section{Publisher's Note}

Springer Nature remains neutral with regard to jurisdictional claims in published maps and institutional affiliations.

\begin{abstract}
Author details
'Department of Biology, Miami University, Oxford, OH 45056, USA. ${ }^{2}$ Nuclear Medicine Department, University of Cincinnati Medical Center, 234 Goodman Street, Cincinnati, OH 45219, USA. ${ }^{3}$ Center for Gene Therapy, The Research Institute at Nationwide Children's Hospital, Columbus, OH 43205, USA. ${ }^{4}$ Department of Human Molecular Genetics and Biochemistry, Sackler Faculty of Medicine, Sagol School of Neurosciences, Tel Aviv University, 69978 Tel Aviv, Israel. ${ }^{5}$ Department of Animal Sciences, Texas A\&M University, College Station, TX 77843-2471, USA. ${ }^{6}$ Department of Ophthalmology, Tufts University School of Medicine, Boston, MA 02111, USA. 'Department of Cell Biology and Human Anatomy, University of California, Davis One Shields Avenue, Davis, CA 95616, USA. ${ }^{8}$ Present Address: Solomon H. Snyder Department of Neuroscience, Johns Hopkins University School of Medicine, Baltimore, MD 21205, USA. ${ }^{9}$ Present Address: Emory Children's Center, Room 410, 2015 Uppergate Drive, Atlanta, GA 30322, USA
\end{abstract}

\section{Received: 5 December 2018 Accepted: 22 January 2019}

\section{Published online: 15 February 2019}

\section{References}

1. Sauer B, Henderson N. Site-specific DNA recombination in mammalian cells by the Cre recombinase of bacteriophage P1. Proc Natl Acad Sci U S A. 1988:85(14):5166-70.

2. Dymecki SM. Flp recombinase promotes site-specific DNA recombination in embryonic stem cells and transgenic mice. Proc Natl Acad Sci U S A. 1996; 93(12):6191-6.

3. Sauer B, McDermott J. DNA recombination with a heterospecific Cre homolog identified from comparison of the pac-c1 regions of P1-related phages. Nucleic Acids Res. 2004;32(20):6086-95.

4. Anastassiadis K, Fu J, Patsch C, Hu S, Weidlich S, Duerschke K, et al. Dre recombinase, like $\mathrm{Cre}$, is a highly efficient site-specific recombinase in $\mathrm{E}$. Coli, mammalian cells and mice. Dis Model Mech. 2009;2(9-10):508-15.

5. Meinke G, Bohm A, Hauber J, Pisabarro MT, Buchholz F. Cre recombinase and other tyrosine recombinases. Chem Rev. 2016;116(20):12785-820.

6. Lakso M, Sauer B, Mosinger B Jr, Lee EJ, Manning RW, Yu SH, et al. Targeted oncogene activation by site-specific recombination in transgenic mice. Proc Natl Acad Sci U S A. 1992;89(14):6232-6.

7. Nagy A, Mar L, Watts G. Creation and use of a Cre recombinase transgenic database. Methods Mol Biol. 2009;530:365-78.

8. Zhao H, Yang Y, Rizo CM, Overbeek PA, Robinson ML. Insertion of a Pax6 consensus binding site into the alphaA-crystallin promoter acts as a lens epithelial cell enhancer in transgenic mice. Invest Ophthalmol Vis Sci. 2004; 45(6):1930-9.

9. Ashery-Padan R, Marquardt T, Zhou X, Gruss P. Pax6 activity in the lens primordium is required for lens formation and for correct placement of a single retina in the eye. Genes Dev. 2000;14(21):2701-11.
10. Yoshimoto A, Saigou Y, Higashi Y, Kondoh H. Regulation of ocular lens development by Smad-interacting protein 1 involving Foxe3 activation. Development. 2005;132(20):4437-48.

11. Kreslova J, Machon O, Ruzickova J, Lachova J, Wawrousek EF, Kemler R, et al. Abnormal lens morphogenesis and ectopic lens formation in the absence of beta-catenin function. Genesis. 2007:45(4):157-68.

12. Rowan S, Conley KW, Le TT, Donner AL, Maas RL, Brown NL. Notch signaling regulates growth and differentiation in the mammalian lens. Dev Biol. 2008; 321(1):111-22.

13. Tronche F, Kellendonk C, Kretz O, Gass P, Anlag K, Orban PC, et al. Disruption of the glucocorticoid receptor gene in the nervous system results in reduced anxiety. Nat Genet. 1999;23(1):99-103.

14. Calera MR, Topley HL, Liao Y, Duling BR, Paul DL, Goodenough DA. Connexin43 is required for production of the aqueous humor in the murine eye. J Cell Sci. 2006;119(Pt 21):4510-9.

15. Cammas L, Wolfe J, Choi SY, Dedhar S, Beggs HE. Integrin-linked kinase deletion in the developing lens leads to capsule rupture, impaired fiber migration and non-apoptotic epithelial cell death. Invest Ophthalmol Vis Sci. 2012;53(6):3067-81.

16. Rodrigues PM, Grigaravicius P, Remus M, Cavalheiro GR, Gomes AL, RochaMartins $\mathrm{M}_{\text {, et }}$ al. Nbn and atm cooperate in a tissue and developmental stage-specific manner to prevent double strand breaks and apoptosis in developing brain and eye. PLoS One. 2013;8(7):e69209.

17. Robertson G, Garrick D, Wu W, Kearns M, Martin D, Whitelaw E. Positiondependent variegation of globin transgene expression in mice. Proc Natl Acad Sci U S A. 1995;92(12):5371-5

18. Milot E, Strouboulis J, Trimborn T, Wijgerde M, de Boer E, Langeveld A, et al. Heterochromatin effects on the frequency and duration of LCR-mediated gene transcription. Cell. 1996;87(1):105-14

19. Webster J, Donofrio G, Wallace R, Clark AJ, Whitelaw CB. Intronic sequences modulate the sensitivity of beta-lactoglobulin transgenes to position effects. Gene. 1997;193(2):239-43.

20. Garrick D, Fiering S, Martin DI, Whitelaw E. Repeat-induced gene silencing in mammals. Nat Genet. 1998;18(1):56-9.

21. Kammandel B, Chowdhury K, Stoykova A, Aparicio S, Brenner S, Gruss P. Distinct cis-essential modules direct the time-space pattern of the Pax6 gene activity. Dev Biol. 1999;205(1):79-97.

22. Carbe $C$, Hertzler-Schaefer $K$, Zhang $X$. The functional role of the Meis/Prepbinding elements in Pax6 locus during pancreas and eye development. Dev Biol. 2012;363(1):320-9.

23. Zhang $X$, Heaney S, Maas RL. Cre-loxp fate-mapping of Pax6 enhancer active retinal and pancreatic progenitors. Genesis. 2003:35(1):22-30

24. Zhang $X$, Rowan S, Yue $Y$, Heaney S, Pan Y, Brendolan A, et al. Pax6 is regulated by Meis and $\mathrm{Pbx}$ homeoproteins during pancreatic development. Dev Biol. 2006:300(2):748-57.

25. Kim TH, Kim BM, Mao J, Rowan S, Shivdasani RA. Endodermal hedgehog signals modulate notch pathway activity in the developing digestive tract mesenchyme. Development. 2011;138(15):3225-33.

26. Wolf $L$, Yang $Y$, Wawrousek $E$, Cvekl A. Transcriptional regulation of mouse alpha A-crystallin gene in a $148 \mathrm{~kb}$ Cryaa BAC and its derivates. BMC Dev Biol. 2008;8:88

27. Cvekl A, Sax CM, Bresnick EH, Piatigorsky J. A complex array of positive and negative elements regulates the chicken alpha A-crystallin gene: involvement of Pax-6, USF, CREB and/or CREM, and AP-1 proteins. Mol Cell Biol. 1994;14(11):7363-76.

28. Macatee TL, Hammond BP, Arenkiel BR, Francis L, Frank DU, Moon AM. Ablation of specific expression domains reveals discrete functions of ectoderm- and endoderm-derived FGF8 during cardiovascular and pharyngeal development. Development. 2003;130(25):6361-74.

29. Robinson ML, Walton NA, Wallace LM, Yang Y. Homozygosity for the Le-Cre transgene is associated with microphthalmia and cataracts in the absence of other engineered genetic changes. Invest Ophthalmol Vis Sci. 2005;46(13):1885

30. Dora NJ, Collinson JM, Hill RE, West JD. Hemizygous Le-Cre transgenic mice have severe eye abnormalities on some genetic backgrounds in the absence of LoxP sites. PLoS One. 2014;9(10):e109193.

31. De Maria A, Bassnett S. Birc7: a late fiber gene of the crystalline lens. Invest Ophthalmol Vis Sci. 2015;56(8):4823-34.

32. Soriano P. Generalized lacZ expression with the ROSA26 Cre reporter strain. Nat Genet. 1999;21(1):70-1.

33. Janbandhu VC, Moik D, Fassler $R$. Cre recombinase induces DNA damage and tetraploidy in the absence of loxP sites. Cell Cycle. 2014;13(3):462-70. 
34. Pugach EK, Richmond PA, Azofeifa JG, Dowell RD, Leinwand LA. Prolonged Cre expression driven by the alpha-myosin heavy chain promoter can be cardiotoxic. J Mol Cell Cardiol. 2015;86:54-61.

35. Harno E, Cottrell EC, White A. Metabolic pitfalls of CNS Cre-based technology. Cell Metab. 2013;18(1):21-8.

36. Schmidt-Supprian M, Rajewsky K. Vagaries of conditional gene targeting. Nat Immunol. 2007;8(7):665-8.

37. Schmidt EE, Taylor DS, Prigge JR, Barnett S, Capecchi MR. Illegitimate Credependent chromosome rearrangements in transgenic mouse spermatids. Proc Natl Acad Sci U S A. 2000;97(25):13702-7.

38. Alford KA, Glennie S, Turrell BR, Rawlinson L, Saklatvala J, Dean JL. Heat shock protein 27 functions in inflammatory gene expression and transforming growth factor-beta-activated kinase-1 (TAK1)-mediated signaling. J Biol Chem. 2007;282(9):6232-41.

39. Arrigo AP. Mammalian HspB1 (Hsp27) is a molecular sensor linked to the physiology and environment of the cell. Cell Stress Chaperones. 2017;22(4): 517-29.

40. Georgakilas AG, Martin OA, Bonner WM. p21: a two-faced genome guardian. Trends Mol Med. 2017;23(4):310-9.

41. Ke JY, Dai CJ, Wu WL, Gao JH, Xia AJ, Liu GP, et al. USP11 regulates p53 stability by deubiquitinating p53. J Zhejiang Univ Sci B. 2014;15(12):1032-8.

42. Deng T, Yan G, Song X, Xie L, Zhou Y, Li J, et al. Deubiquitylation and stabilization of p21 by USP11 is critical for cell-cycle progression and DNA damage responses. Proc Natl Acad Sci U S A. 2018;115(18):4678-83.

43. Phatarakijnirund V, Mumm S, McAlister WH, Novack DV, Wenkert D, Clements $\mathrm{KL}$, et al. Congenital insensitivity to pain: fracturing without apparent skeletal pathobiology caused by an autosomal dominant, second mutation in SCN11A encoding voltage-gated sodium channel 1.9. Bone. 2016;84:289-98

44. Stern R. Hyaluronidases in cancer biology. Semin Cancer Biol. 2008;18(4): 275-80

45. Cvekl A, Zhang X. Signaling and gene regulatory networks in mammalian lens development. Trends Genet. 2017:33(10):677-702.

46. Jeannotte L, Aubin J, Bourque S, Lemieux M, Montaron S, Provencher S-PA. Unsuspected effects of a lung-specific Cre deleter mouse line. Genesis. 2011;49(3):152-9.

47. Li Y, Choi PS, Casey SC, Felsher DW. Activation of Cre recombinase alone can induce complete tumor regression. PLoS One. 2014;9(9):e107589.

48. Semprini S, Troup TJ, Kotelevtseva N, King K, Davis JR, Mullins L, et al. Cryptic loxP sites in mammalian genomes: genome-wide distribution and relevance for the efficiency of BAC/PAC recombineering techniques. Nucleic Acids Res. 2007;35(5):1402-10.

49. Wallace LM, Moreo A, Clark KR, Harper SQ. Dose-dependent toxicity of humanized Renilla reniformis GFP (hrGFP) limits its utility as a reporter gene in mouse muscle. Mol Ther Nucleic Acids. 2013;2:e86.

50. Huang WY, Aramburu J, Douglas PS, Izumo S. Transgenic expression of green fluorescence protein can cause dilated cardiomyopathy. Nat Med. 2000;6(5):482-3.

51. Agbulut O, Coirault C, Niederlander N, Huet A, Vicart P, Hagege A, et al. GFP expression in muscle cells impairs actin-myosin interactions: implications for cell therapy. Nat Methods. 2006;3(5):331.

52. Agbulut $\mathrm{O}$, Huet $\mathrm{A}$, Niederlander $\mathrm{N}$, Puceat M, Menasche P, Coirault C. Green fluorescent protein impairs actin-myosin interactions by binding to the actin-binding site of myosin. J Biol Chem. 2007;282(14):10465-71.

53. Ansari AM, Ahmed AK, Matsangos AE, Lay F, Born LJ, Marti G, et al. Cellular GFP toxicity and immunogenicity: potential confounders in in vivo cell tracking experiments. Stem Cell Rev. 2016;12(5):553-9.

54. Feil R, Brocard J, Mascrez B, LeMeur M, Metzger D, Chambon P. Ligandactivated site-specific recombination in mice. Proc Natl Acad Sci U S A. 1996;93(20):10887-90.

55. Shi $Y$, Bassnett $S$. Inducible gene expression in the lens using tamoxifen and a GFP reporter. Exp Eye Res. 2007:85(5):732-7.

56. Hoang TV, Kumar PK, Sutharzan S, Tsonis PA, Liang C, Robinson ML. Comparative transcriptome analysis of epithelial and fiber cells in newborn mouse lenses with RNA sequencing. Mol Vis. 2014;20:1491-517.

57. Gimenez E, Montoliu L. A simple polymerase chain reaction assay for genotyping the retinal degeneration mutation (Pdeb(rd1)) in FVB/N-derived transgenic mice. Lab Anim. 2001;35(2):153-6.

Ready to submit your research? Choose BMC and benefit from:

- fast, convenient online submission

- thorough peer review by experienced researchers in your field

- rapid publication on acceptance

- support for research data, including large and complex data types

- gold Open Access which fosters wider collaboration and increased citations

- maximum visibility for your research: over $100 \mathrm{M}$ website views per year

At BMC, research is always in progress.

Learn more biomedcentral.com/submissions 